Florida International University FIU Digital Commons

FIU Electronic Theses and Dissertations

University Graduate School

7-21-1997

\title{
Intra-organizational turnover in a self-selective team environment
}

Sharon Anne Israel Dolfi

Florida International University

DOI: $10.25148 /$ etd.FI15101210

Follow this and additional works at: https://digitalcommons.fiu.edu/etd

Part of the Psychology Commons

\section{Recommended Citation}

Dolfi, Sharon Anne Israel, "Intra-organizational turnover in a self-selective team environment" (1997). FIU Electronic Theses and Dissertations. 3073.

https://digitalcommons.fiu.edu/etd/3073

This work is brought to you for free and open access by the University Graduate School at FIU Digital Commons. It has been accepted for inclusion in FIU Electronic Theses and Dissertations by an authorized administrator of FIU Digital Commons. For more information, please contact dcc@fiu.edu. 
FLORIDA INTERNATIONAL UNIVERSITY

Miami, Florida

INTRA-ORGANIZATIONAL TURNOVER IN A SELF-SELECTIVE

TEAM ENVIRONMENT

A dissertation submitted in partial satisfaction of the requirements for the degree of

DOCTOR OF PHILOSOPHY

IN

PSYCHOLOGY

by

Sharon Anne Israel Dolfi

1997 
To: Dean Arthur W. Herriott College of Arts and Sciences

This dissertation, written by Sharon Anne Israel Dolfi, and entitled Intra-Organizational Turnover in a Self-Selective Team Environment, having been approved in respect to style and intellectual content, is referred to you for judgment.

We have read this dissertation and recommend that it be approved.

Margaret Bull Kovera

William Rando

Juan I. Sanchez

Scott L. Fraser, Major Professor

Date of Defense: July 21, 1997

The dissertation of Sharon Anne Israel Dolfi is approved.

Dean Arthur W. Herriott

College of Arts and Sciences

Dr. Richard L. Campbell

Dean of Graduate Studies

Elorida International University, 1997 
COPYRIGHTC 1997 by Sharon Anne Israel Dolfi

All rights reserved 
I dedicate my degree to my family, for their support and love. 


\section{ACKNOWLEDGMENTS}

Sincere appreciation is extended to Margaret Bull Kovera, William Rando, and Juan Sanchez for their time, advice, and constructive criticism. I wish to express very special thanks to my major professor, scott Fraser, for his support, encouragement, and teachings throughout my graduate school training.

To the firefighters, paramedics and emergency medical technicians who dedicate their days and nights to helping those in need: Thank you. 


\section{ABSTRACT OF THE DISSERTATION \\ INTRA-ORGANIZATIONAL TURNOVER IN A SELF-SELECTIVE \\ TEAM ENVIRONMENT}

by

Sharon Anne Israel Dolfi

Florida International University, 1997

Professor Scott Eraser, Major Professor

Four-hundred twenty-seven firefighter/paramedics and firefighter/emergency medical technicians completed questionnaires regarding past and current turnover decisions. The employees, who work in teams of either three or four, have a collective bargaining benefit that allows them to "bid for" (request) new positions/teams every six months; positions are awarded on the basis of seniority. Because employees are leaving neither the organization nor their job, the "bid" process creates intra-organizational turnover on a regular basis. It was hypothesized that those individuals higher in teamwork/social cohesion expectations, higher in interpersonal orientation, and lower in conflict 
tolerance would report placing greater importance on interpersonal reasons (teamwork/social cohesion) in past bid/assignment decisions. Creation of a conflict tolerance scale was the goal of a preliminary study. It was further hypothesized that current bid/assignment satisfaction would predict the current turnover decision (during the cycle in which the study was conducted), and that past individual turnover frequency would also predict current turnover. All hypotheses were supported. 
I. INTRODUCTION.

II. LITERATURE REVIEW. . . . . . . . . . . . . . . . 5 Teams: Definitions and Characteristics. . . . . . 5 Self-Selected Groups/Teams. . . . . . . . . . . 7 Turnover. . . . . . . . . . . . . . . 8 Team Turnover. . . . . . . . . . . . . . 15 Interdependence and Investment Models. . . . . . 21 Met Expectations. . . . . . . . . . . . . 26 Satisfaction with Teamwork. . . . . . . . . . . . . . . . . 28 Social Cohesion, Social Identity,

Relational Demography. . . . . . . . . . . 31 Interpersonal Orientation. . . . . . . . . . . 38 Conflict Tolerance. . . . . . . . . . . . . 39

CONELICT TOLERANCE SCALE DEVELOPMENT STUDY

III. METHOD. . . . . . . . . . . . . . . .45

Participants. . . . . . . . . . . . . .45 Materials. . . . . . . . . . . . . 4 45 Procedure. . . . . . . . . . . . . 46

IV. RESULTS. . . . . . . . . . . . . . 47

V. DISCUSSION. . . . . . . . . . . . . .51

FOCAL STUDY

VI. METHOD. . . . . . . . . . . . . . . .53 Participants. . . . . . . . . . . . . . . . . 53 Materials. . . . . . . . . . . . . 54 Procedure. . . . . . . . . . . . . . 57

Distribution. . . . . . . . . . . . . . 57

Telephone Notification and Solicitation of Response................ . . . . . 88 Collection. . . . . . . . . . . . . . . . 59

VII. RESULTS. . . . . . . . . . . . . . . 60 Hypothesis 1.............. . . . . . . . . 65 Hypothesis 2a. . . . . . . . . . . . . 68 Discriminant Analysis: Addendum to Hypothesis 2a. .70 Hypothesis 2b. . . . . . . . . . . . . 73 Exploratory Analyses. . . . . . . . . . . .75 
VIII. DISCUSSION. . . . . . . . . . . . . . . . .77 Factor Analysis (Principal Components):

Reasons for Bid/Assignment Decisions. . . . . . .77 Reliability Analyses. . . . . . . . . . . . .77 Correlation Matrix. . . . . . . . . . . .78 Hypothesis 1. . . . . . . . . . . . . .79

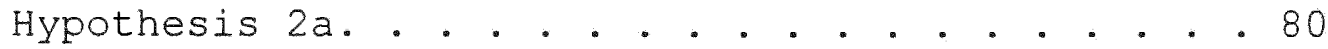
Discriminant Analysis: Addendum to Hypothesis 2a. .81 Hypothesis $2 \mathrm{~b}$. . . . . . . . . . . . . . 82 Exploratory Analyses. . . . . . . . . . . .83 Limitations. . . . . . . . . . . . . . . 84 Theoretical Support for the Investment Model. . . .85 Organizational Implications. . . . . . . . . . 88 General Contributions. . . . . . . . . . . . 91 Turnover. . . . . . . . . . . . . . . .91 Future Research. . . . . . . . . . . . 93

IX. LIST OF REFERENCES. . . . . . . . . . . . .95

X. APPENDICES. ............... 108 XI. VITA. . . . . . . . . . . . . . 116 


\section{LIST OF TABLES}

CONFLICT TOLERANCE SCALE DEVELOPMENT STUDY

TABLE

PAGE

1 Conflict Tolerance Scale Reliability:

28 Pilot-tested Items. . . . . . . . . . . .48

2 Conflict Tolerance Scale Reliability:

12 Selected Items. . . . . . . . . . . .49

3 Frequency Table - Conflict Tolerance Scores:

Pilot Test - 12 Selected Items. . . . . . . 50

FOCAL STUDY

TABLE

PAGE

4 Eactor Analysis (Principal Components):

Reasons for Bid/Assignment Decisions. . . . . . 61

5 Reliability Analyses of Scales. . . . . . . . 62

6 Means, Standard Deviations, and

Correlation Matrix. . . . . . . . . . . 63

7 Multiple Regression Predicting Importance of

Interpersonal Reasons (Teamwork/Social

Cohesion) in Bid/Assignment Decisions. . . . . 66

8 Multiple Regression Predicting Importance of

Other Reasons in Bid/Assignment Decisions. . . . 67

9 Analysis of Variance: Current Bid/Assignment

Satisfaction by Turnover Decision. . . . . . 69

10 Discriminant Analysis: Prediction of Turnover

by Current Bid/Assignment Satisfaction

Individual Items. . . . . . . . . . . . . 71

11 Crosstabulations/Chi-Square: Individual

Turnover Frequency and Turnover Decision. . . . 74 


\section{INTRODUCTION}

Selection of team members is generally a task of organizational leaders or managers. Teams formed for different purposes (i.e., production teams, customer service teams, executive teams) may perform better with different combinations of members (skill levels, personalities, etc.) (Klimoski \& Jones, 1995), but it is usually those in charge who make selection decisions. Jin (1993), using an experimental design, found that voluntary teams (in which the members chose each other) performed better and displayed higher motivation than assigned teams. Many, however, have discussed the "two-sided coin" with respect to such teams (Gardenswartz \& Rowe, 1994). The high levels of cohesion found in voluntary teams may lead to either high or low productivity, depending upon group standards (Seashore, 1954).

The present research took advantage of an opportunity to study an organization comprised of self-selected teams. The first hypothesis of the focal study examined the use of interpersonal reasons (teamwork and social cohesion) in team selection, and can, thus, be described as a policy-capturing investigation. The second hypothesis examined differences between those that were currently changing teams and those 
that were staying, in order to better understand turnover within an organization.

Through a collective bargaining benefit, the participating fire rescue workers have the opportunity to "bid for" positions throughout the department. Once an employee holds a "bid position," it "belongs" to the employee as long as desired. Although final "bids" are awarded by seniority, employees are usually able to obtain one of their prioritized preferences. (Teams in the study were defined as a group of three or four employees who are assigned to the same station, vehicle, and shift; team members remain in close proximity to each other throughout the entire shift.) This employee benefit allowed for the unusual study of actual turnover (as a dependent variable) in an arena where employees select their positions and coworkers. Independent variables were current bid/assignment satisfaction and past individual turnover frequency. As described, turnover was defined as leaving one team/assignment for another team/assignment within the organization: "Intra-Organizational Turnover."

The short (six-month) "bid periods" provided the additional opportunity to study past turnover in an environment where "quitting/choosing a team" is an employee right. Therefore, this study was also able to examine the importance of interpersonal reasons (teamwork/social 
cohesion) in past bid/assignment decisions (whether to stay or leave, and which assignment to "bid for"). This "importance" was another dependent variable. The hypothesized predictors (independent variables) are described below.

Almost all of the firefighter's/paramedic's formal job is based on teamwork, ranging from performing Advanced Cardiac Life Support to handling station duties. The homelike environment of fire rescue stations provides the additional opportunity to study social cohesion on an intense level. Most organizations have a social component (e.g., coffee breaks, lunches with co-workers, occasional social events) which may affect work tasks. Fire rescue workers "on 24-hour shifts" are essentially living together (cooking, sleeping, etc.). It could be inferred, therefore, that social cohesion in such a setting would be an important part of the work experience, and should be considered along with more formal aspects of teamwork.

Because these employees have the ability to transfer stations every six months, most have had the opportunity to work with several different teams. Therefore, it was possible to study the effect of experience (leading to expectations) regarding teamwork/social cohesion on the importance of interpersonal reasons in past bid/assignment decisions. Other hypothesized predictors were interpersonal 
orientation (importance of interpersonal relationships) and conflict tolerance. Creation and pilot testing of a conflict tolerance scale comprised the preliminary study.

To summarize, Hypothesis 1 predicted that three variables (expectations of teamwork/social cohesion, interpersonal orientation, and conflict tolerance) would predict the importance of interpersonal reasons (teamwork/social cohesion) in past bid/assignment decisions. Hypothesis 2 a predicted that current bid/assignment satisfaction would be related to current turnover. Hypothesis $2 \mathrm{~b}$ predicted that past individual turnover frequency would be related to current turnover. 


\section{LITERATURE REVIEW}

Because the selection of teams is an important part of the turnover decision in this organization, the literature review begins with a brief introduction to teams, team characteristics, and self-selected teams begins the literature review. Following these sections are reviews of the turnover literature, and two relevant theoretical areas (interdependence/investment models, and met expectations). Four more areas of pertinent research are then reviewed: satisfaction with teamwork; social cohesion, social identity, and relational demography; interpersonal orientation; and conflict tolerance. Teams: Definitions and Characteristics

In order to distinguish true organizational work groups (teams) from other types of groups, Hackman (1990) described attributes of teams: they are distinguishable; "members are dependent upon one another for some shared purpose"; "they have one or more tasks to perform"; and "they operate in an organizational context" (i.e., the group "manages relations with other individuals or groups in the larger social. system" (p. 4). Important to the present research, Salas, Dickinson, Converse, and Tannenbaum (1992) included another 
attribute: teams have a "limited life-span of membership" (p. 4).

It has also been said that the most "distinguishing" characteristics of teams are 1) that they adapt (their behavior changes based upon goals and environmental conditions) and 2) that they are "dynamic" (in order to adapt) (Coovert, Craiger, \& Cannon-Bowers, 1995, p. 155). Individual teams also have personal "team characteristics" (related to size, communication patterns, team climate, and authority structure). Such characteristics affect performance, as well as being affected by task characteristics and demands, external conditions, and member resources (Goodman, Ravlin, \& Argote, 1986, p. 3). It is these more "fluid" and "active" understandings of teams that provided a foundation for the current study. The team members constantly respond to change (in the emergency medical sector, in chain-of-command, in procedural requirements, and in customer demands). In addition, there are group composition changes (the subject at hand). These changes, made for personal and practical reasons, have the power to affect all other aspects of the team experience, including performance.

Although self-selection, itself, is not a focal point of the present study, it is important as a basis for the turnover choices made by the participants. Therefore, a 
brief literature review of self-selection in groups and teams is included below.

Self-selected Groups/Teams

Because it is often not practical to allow, or experiment with allowing, workers to choose their own group of teammates, there is not much literature in this area. One of the most relevant articles is quite old (Van Zelst, 1952), but strongly demonstrated the potential of selfselection in increasing productivity and satisfaction. Carpenters and bricklayers who chose their teammates scored higher in job satisfaction, displayed virtually no turnover, and saved money on materials and labor costs, compared to those who were assigned to groups. These workers, in a manner similar to those in the present study, were required to be "adept at all phases" (p. 301) of the work product and, thus, were particularly suited to self-selection. Jin (1993) recently demonstrated that self-selection led to higher work motivation and better performance. Tziner \& Vardi (1982) found that cohesion through selfselection interacted with command style, when performance was assessed. Group cohesiveness, a direct result of selfselection, was demonstrated in terms of social and emotional dependence, and attraction. Their study population (tank crews) is relevant to this study, because they, like firefighters/paramedics, had job duties comprised of 
"interdependent tasks" (p. 769). Also, like firefighters and paramedics, the crews essentially lived together. As an extension of such research, the present study examined the two-fold privilege of choosing one's teammates and being able to leave a team when desired. The next section reviews research in the area of turnover, the focus of the present study.

Turnover

Although the literature regarding team turnover is somewhat limited (described below), turnover itself has been extensively studied. Several classic investigations and reviews laid the foundation for today's complex models and analyses. Over 40 years ago, Brayfield and Crockett (1955) provided support for the idea that job satisfaction is related to employment stability, both in terms of turnover and absenteeism, while also calling for more rigorous research. Twenty years later, Porter and Steers (1973) strengthened this argument, while adding the caveat that job satisfaction should be described in terms of an individual's met expectations (discussed below). This was an important point, because simple job satisfaction scales only measure satisfaction, itself. This research showed that satisfaction is really a relative term, based upon individuals' unique expectations. An unhappy individual who 
did not expect to be satisfied may stay indefinitely in their job.

In Porter and Steer"s review of turnover research, four categories of factors related to turnover were described: organization-wide (e.g., pay, promotion), immediate work group (e.g., supervision, co-worker relations), job content, and individual (e.g., age, tenure, personality, etc.). This summary expanded our understanding that turnover was not simply an individual decision based upon simple unhappiness, and paved the groundwork for the more complex studies described below.

Mobley (1977) demonstrated that there are many "intermediate linkages" between job dissatisfaction and turnover. "Thinking of quitting," "evaluating alternatives," and "comparing alternatives," (p. 238) were shown to be important to the final decision. (The issue of alternatives will be discussed later as an important part of Investment Theory.) This study also strongly recognized the idea of alternate forms of withdrawal, such as absenteeism and "passive job behavior" (p. 237). This was significant because both of these consequences are especially important to productivity and/or organizational profit (the "bottom 1 ine").

One year later, Mobley, Horner, and Hollingsworth (1978) tested a similar model utilizing hospital employees. 
They found that, although turnover was correlated with job satisfaction, only "thinking about quitting" and "intending to quit" were predicted by the hypothesized decision process. This illustrated the importance of "cognitive and behavioral phenomena in addition to the affective experience of job satisfaction" (p. 413-4). The present study focuses only on actual turnover decisions. As explained later, this is appropriate because of the "easier" decision being made. Those changing teams did not lose anything in terms of pay, benefits, or job duties.

In a often-cited study the following year, Mobley and his colleagues (Mobley, Griffeth, Hand, \& Meglino, 1979) added another important dimension to a possible model: consideration of present and predicted future satisfaction/attraction/utility of one's current situation and possible alternatives. It was also formally acknowledged that variables not directly related to the job itself enter into the turnover decision. Subsequent research has questioned the value of some model components, such as perceived alternative employment opportunities (Miller, Katerberg, \& Hulin, 1979), and added other components, such as preemployment expectancies and organizational commitment (Michaels \& Spector, 1982). These studies are particularly relevant because of their focus on 
alternatives, expectancies, and commitment. These variables are all components of the Investment Model described later.

The numerous variables linked (directly/indirectly and in varying degrees) to turnover has raised the need for causal modeling (Cotton \& Tuttle, 1986). One fairly recent attempt (Hom, Carankias-Walker, Prussia, \& Griffeth, 1992) utilized structural equation modeling to demonstrate that although Mobley et al. (1978) "fit" better than other models, its explanatory power was lacking. Strong moderators found included occupational differences, turnover base rates, and unemployment rates. The importance of these moderators is understandable. The question of turnover is very complex; it reflects individual attitudes and differences, personal economic need, the job market, etc. Related to the above question of unemployment, Muchinsky and Morrow (1980) emphasized the importance of adding economic factors to turnover models. They stated that the link between individual/work variables and turnover would be stronger under prosperous conditions, an hypothesis confirmed by Carsten and spector (1987). Muchnisky and Morrow's paper, however, may be better known for its recognition that turnover consequences extend beyond affecting an individual's happiness. They detailed four types of consequences: individual, organizational-social (e.g., morale, ), organizational-economic, and societal 
(e.g., labor markets, unemployment, social security). These are similar to the factors described by Porter and steer's (1973) (above) as precipitating turnover.

As discussed earlier, intentions are a very important part of the phenomenon of turnover. Steel and Ovalle (1984) found, through meta-analysis, that intentions were more predictive of turnover than job satisfaction, satisfaction with the work itself, or organizational commitment. Similar findings have been reported by Michaels and Spector (1982) and Tett and Meyer (1993). The latter researchers' metaanalytical findings showed that withdrawal intentions and cognitions moderated nearly all relationships between attitudes and turnover. Again, intentions are unusually easier to "act upon" in the present study because employees lose little in terms of duties, pay, and benefits.

A more qualitative approach to the phenomenon of turnover was undertaken by Lee and colleagues (Lee \& Mitchell, 1994; Lee, Mitchell, Wise, \& Fireman, 1996). These articles described a model of turnover stemming from a "shock to the system": "a very distinguishable event that jars employees toward deliberate judgments about their jobs and, perhaps, to voluntarily quit their job" (Lee \& Mitchell, 1994, p. 60). "Shocks" are not necessarily negative. The decision tree leads to the personal question of whether or not the shock is easily handled (through 
experience or observation), and continues to consideration of job satisfaction and alternatives.

Most turnover models, they stated, are far too simplistic, not considering the many ways an employee can leave an organization. For example, traditional models do not easily account for those who quit with little deliberation. Furthermore, various reasons (besides affect) may be responsible for turnover; people often leave without alternatives; and people often have "shocks" unrelated to the job itself. The latter article described a successful test of the model, acknowledging that although the research does not cause a "paradigmatic shift," it does not represent the "status quo" (Lee et al., 1996, p. 34). Although it may not cause a change in the direction of traditional turnover research, it has added a different and interesting dimension.

This qualitative line of research is important because it raises issues often "glossed over" by more traditional studies. Strict quantitative studies often ignore, probably in a conscious manner, those who do not leave for mainstream reasons or in mainstream ways. Perhaps this is necessary in order to understand the usual paths and make organizational decisions accordingly. Nevertheless, the qualitative research reminds us that these are, in fact, individual persons being studied. 
There are also strong critiques found in the turnover literature. In 1979, Muchinsky and Tuttle detailed eight methodological problems they believed were problematic for turnover research. These included measurement problems, lack of differentiation between voluntary and involuntary turnover, lack of cross-validation, and lack of subgroup analyses. Two years later, Steers and Mowday (1981) described nine shortcomings of most turnover models. They claimed that, for example, then-current models ignored feedback loops, ignored other attitudes like organizational commitment, and ignored the fact that dissatisfied employees have other alternatives within the organization, such as trying to improve their situation.

Most of the concerns of these earlier articles have been addressed, as turnover research has continued attracting interested investigators. Limitations that continue to exist for turnover research include problems with organizational records (i.e., personnel files), and the ambiguity of the word "voluntary" in regard to turnover (e.g., what is retirement and health-related turnover?) (Campion, 1991). Although there will always be room for improvement, the literature regarding organizational turnover has grown tremendously: in volume, in complexity, and in understanding. 
The next section focuses on team turnover research, a the more specific area of research relevant to the present study.

\section{Team Turnover}

There have been some studies regarding turnover or withdrawal in team settings. Hellman (1994) found that simple participation in committee work made members more likely to remain a part of the committee, while webber (1974) focused on which ethnic groups were more likely to participate in multi-ethnic teams of students. These studies" focus on individual differences is similar to the present study.

Gear, Marsh, and Sergent (1985) linked withdrawal behavior in a management team to perception of individual conflict, while a very different sort of conflict (approachavoidant conflict regarding playing in front of others) caused members of a pool league to quit (Chick, Roberts, \& Romney, 1991). Similar to Gear, et al., the present study examined individual conflict tolerance and how it relates to turnover decisions.

Other turnover studies involving groups have revolved around the issue of group (rather than organizational) heterogeneity and demography (see also Relational Demography below). Wiersema and Bird (1993) found that demographic heterogeneity among top management team members led to group 
turnover. O'Reilly, III, Caldwell, and Barnett (1989) reported similar results with convenience store work groups, explaining lack of social integration to be the link between the two variables. In another similar study, George and Bettenhausen (1990) found that group cohesiveness and leaders' positive mood were negatively related to turnover. These studies' focus on interpersonal behavior and turnover is similar to the present study. The present study did not examine group differences, but, instead, explored the importance of interpersonal reasons in turnover decisions. This "importance," however, reflects experienced group dynamics.

All of the team/group turnover studies measured turnover or withdrawal as a decision to stay, leave, or withdraw from a group and/or the organization. There was no measure of desire to leave in order to join another group or team, as in this study. Due to the unique bid system, this study was able to "hold constant" all other organizational factors that normally affect turnover. Team members who left their team retained their same position, seniority, job duties, benefits, salary, etc. This situation allows a different (more controlled) test of turnover in which individual factors (in team turnover decisions), rather than just the turnover decision itself, can be studied. 
One team turnover study (Jackson, Brett, Sessa, Cooper, Julin, \& Payronnin, 1991) briefly discussed turnover from one group to another. In a discussion of their measures, they explained that turnover from the focal top management team was assumed to refer to organizational turnover. It was theoretically possible, they said, but not verifiable, that some of the employees could have joined other teams. This, however, was not a part of the investigation.

In addition to the need for research on group turnover, there is also a lack of research regarding simple turnover within an organization. A notable exception is Chao, O'Leary-Kelly, Wolf, Klein, \& Gardner (1994) who found differences in socialization proficiencies between those who remained in the same job, those who changed jobs within an organization, and those who changed both jobs and organizations. There were no participants, however, that solely changed location or unit within an organization while keeping the same job; the turnover described within the organization involved leaving one job for another.

The present study, on the other hand, considered complete "Intra-organizational Turnover"; that is, leaving a work team, but remaining with the same organization, and doing the same job. Employees were asked about importance of reasons for past bid/assignment decisions (whether to stay with, or leave, a team/assignment, and choosing a new 
team/assignment). (Knowledge of potential new teammates depends upon how many positions are vacant at a given station, seniority of those interested, and knowledge of who will be "bidding" for the position(s)). Therefore, this study focused on a unique aspect of turnover (the reported importance of specific reasons for past bid/assignment decisions), in addition to the actual current turnover decision.

The consideration of Intra-Organizational Turnover, rather than organizational turnover, encourages study of particular factors (i.e., satisfaction with teamwork, social cohesion) used in the turnover decision process. This is because, as mentioned earlier, all variables such as pay, benefits, duties, seniority, etc. are held constant. This fact allows the more detailed study of variables used in the turnover decision.

The decision to leave an organization theoretically involves the weighing of costs and benefits (financial and otherwise) involved in leaving a known position for the unknown. The participants in this study did not decide whether or not to leave their jobs. They, instead, made the "Iuxurious" decisions of where to work (with the knowledge that basic benefits and job characteristics would remain the same). It should be acknowledged that such decisions are 
fundamentally different from the classic question of turnover.

Most turnover research has, rightfully, focused upon reasons for leaving and the somewhat complex paths taken to reach that point. To that end, we have learned a great deal about individual and organizational factors related to turnover. Hypothesis 1 of the present study asks a different question, and in doing so, provides different information. The query is not related to when a person leaves, but to what kind of person uses what kind of information when making the decision. Hypotheses $2 \mathrm{a}$ and $2 \mathrm{~b}$ do look at differences between those that stay and those that leave (more similar to past research).

In summation, two dependent turnover variables were utilized in the focal study's hypotheses: importance of reasons in past bid/assignment decisions (interpersonal reasons [teamwork/social cohesion] and "other" reasons) (Hypothesis 1), and the actual current turnover decision (Hypothesis 2). Hypothesis 1 was a policy-capturing question: what information was used by whom when making turnover decisions? The hypothesis was that those higher in expectations (of teamwork and social cohesion), higher in interpersonal orientation, and lower in conflict tolerance would have been more likely to place greater importance on interpersonal reasons in the decision process. Therefore, 
the actual turnover question was not important for Hypothesis 1 .

Use of actual turnover (rather than intent) in Hypothesis 2 is significant. These two variables are related but different phenomena (Tett \& Meyer, 1993). Furthermore, actual turnover is the true variable of interest in turnover studies. Hypothesis 2 a examined the relationship between current bid/assignment satisfaction and the turnover decision.

One additional issue of turnover was studied:

Hypothesis $2 \mathrm{~b}$ examined whether the current turnover decision is related to past individual turnover frequency. Though not part of a true longitudinal study, the question does link past and present behavior. There are many longitudinal studies in the turnover literature. The research question, however, has usually involved prediction of turnover by attitudinal and behavioral variables measured over a period of time (Graen \& Ginsburgh, 1977; Irving \& Meyer, 1994; Sheridan, 1985; Youngblood, Mobley, \& Meglino, 1983). The link between past and present turnover, particularly within the same organization, is a unique line of inquiry.

Pragmatically, it is usually not possible to study a question such as this. Turnover is usually not "offered" to employees as it is to this study's participants. In most circumstances, an individual must, of their own accord, make 
the turnover issue salient. The "regular turnover opportunities" afforded these individuals afforded a unique opportunity for study.

The next section reviews the literature of Interdependence Theory and Investment Models. Although it was formulated to explain personal relationships, the Investment Model provides a clear basis for the present research. Interdependence and Investment Models

Social psychological research regarding interdependence theory (Thibaut \& Kelley, 1959; Kelley \& Thibaut, 1978) provides a foundation for understanding turnover in the present study. Interdependence in relationships is based upon comparison levels (CL), "the standard(s) against which the member evaluates the 'attractiveness' of the relationship or how satisfactory it is." There is also a comparison level for alternatives (CL alt), or "the lowest level of outcomes a member will accept in the light of available alternative opportunities." If the current outcomes of the relationship "drop below" the CL alt, the person will leave the relationship. (Thibaut \& Kelley, 1959, p. 21) Interdependence theory may also be applied to groups, with individuals remaining only if "membership in the [group] puts each member above his CL alt" (Thibaut \& Kelley, 1959, p. 192). In the present study, each bid 
period allowed the employee another chance to weigh their situation against possible alternatives.

Based upon interdependence theory and Hirschman's (1970) work regarding individual and organizational responses to economic/political decline, Rusbult and colleagues (Rusbult, Zembrodt, \& Gunn, 1982; Rusbult, 1983) developed a theory explaining when and why partners choose to stay in/leave a relationship. Their Investment Model states that commitment to maintaining a relationship is "computed" as follows:

Commitment $=$ Satisfaction + Investments - Alternatives (Satisfaction refers to prior satisfaction [before current problems started]). Possible responses are categorized as follows: 1) active/constructive: voice (communication, counseling, etc.), 2) active/destructive: exit (leave the relationship, 3) passive/constructive: loyalty (hope and wait), and 4) passive/destructive: neglect (avoid interaction, ignore partner or treat partner badly). The 1982 study found that constructive responses resulted from high prior satisfaction and investments, and destructive responses resulted from low prior satisfaction and investments. Although good alternatives led to constructive responses, and poor alternatives led to destructive responses, this influence was much weaker than satisfaction and investments. 
The Investment Model can be applied to the present research, with "exit" being defined as turnover (leaving the team/assignment). The alternatives for all personnel were good in terms of receiving the same pay/benefits and enjoying similar job conditions. Higher seniority would, however, have offered an individual more choices, and more likelihood of obtaining a first choice; in other words, better alternatives. The Expectations variable in the present study "tied-in" to alternatives, because, although alternatives may have existed, someone with low expectations may not have expected another situation to be better.

Investment in the job itself would not be a relevant issue, because turnover did not mean loss of the job, seniority, retirement, etc. Investment in the team relationship would vary by individual and team, but was probably related to length of time working together and team cohesion. (Unfortunately, these variables (particularly, length of time working together) would be very difficult to measure, because the teams do not change as units. Rather, one, two, three, or four members may change each bid period.) A given individual with the capability of developing, and desire (interpersonal orientation) to develop, a strong team bond would have had to find the "right" teammates in order for investment to become a salient issue. Because of the ease and acceptance of 
changing "bids," investment may not have been an important issue for most individuals.

Prior satisfaction with the assignment could probably add the most (of the three components) to this application of the Investment Model (depending upon the assignment, the team, and their interaction). Prior satisfaction with the team relationship would depend upon the true nature of this relationship, as well as individual characteristics (such as conflict tolerance and interpersonal orientation).

The model might explain the bid decision cycle as follows: At the time of the bid vacancy announcements, the firefighters would assess their current satisfaction. If they were not satisfied, they would "contemplate" their situation further. Turnover would be expected from firefighters that have had low prior satisfaction in the position and/or with the team, do not feel a great sense of investment in either the position or team relationship, and view their alternatives as good.

Studies and meta-analyses have supported and better explained the Investment Model (Farrell \& Rusbult, 1981; Farrell \& Rusbult, 1992). Important to the present study, the role of alternatives is one area in which knowledge has increased. It has been found that better alternatives promote exit and voice, rather than neglect (Rusbult \& Loery, 1985; Farrell \& Rusbult, 1992). Rusbult, Farrell, 
Rogers, and Mainous III (1988), however, did not find a connection between alternatives and neglect, suggesting that quality of alternatives may create "asymmetrical" effects. Although high quality alternatives may promote active steps (exit or voice), poorer quality alternatives may not encourage "greater and greater passivity" (p. 616). This seems to be an appropriate argument for the present study's participants. Better alternatives may have encouraged a firefighter to "bid out" of a station, but poorer quality of alternatives would probably not have caused increasingly poorer working relationships in their positions.

Also relevant is a longitudinal study of turnover (Rusbult \& Farrell, 1983), which examined rewards, costs, alternatives and investments. They found that there is a "process of change," that "distinguishes between those that stay and those that leave" (p. 437). This process is characterized by declining rewards, increasing costs, declining investment size, and improvement in alternative quality for those that leave. In the present study, such ongoing changes might have made the difference to someone who was content six months prior, but was now ready to "bid out." The short bid-cycle, thus, would seem to encourage an ongoing evaluation of one's situation.

There are many similarities in the turnover and Investment Model literature. The "process of change" 
described above is reminiscent of the importance of intentions in turnover decisions. As mentioned earlier, alternatives are important in both bodies of research. Alternatives can be affected by economic factors in both turnover (e.g., job market) and Investment Model (e.g., possible reduction in living standard) applications. Commitment is, of course, central to both turnover (in the form of organizational commitment) and the Investment Model. Finally, both areas of research deal with satisfaction, but in different ways. The Investment Model looks at satisfaction prior to current experienced problems, while turnover considers current satisfaction.

The next section, Met Expectations, is discussed for two reasons. First of all, expectations fof teamwork and social cohesion) was a predictor variable in Hypothesis 1. Secondly, Met Expectations research is closely tied to the Investment Model.

Met Expectations

Porter and Steer's (1973) original concept of met expectations referred to "the discrepancy between what a person encounters on the job in the way of positive and negative experiences and what he expected to encounter" (p. 152). Although a recent critique (Irving \& Meyer, 1994) suggested that providing positive experiences is more helpful than meeting expectations, a strong relationship has 
been demonstrated between met expectations and intent to leave a job (Wanous, Poland, Premack, \& Davis, 1992). A related stream of research has given credit to realistic job previews (Premack \& Wanous, 1985) in contributing to met expectations.

Because the present study is not focused on newcomers, the "realistic job preview" could be equated to previous experience with other teams, and the met expectations are whether or not the current situation has been "in sync" with that experience. The question asked was whether good or bad experience with teamwork and social cohesion affected subsequent bid/assignment decisions. One thought process might be: "I've experienced teamwork problems in most of the groups with whom I've worked; why should I think the next group will be any better?; I might as well stay where I am." Alternatively, an employee might think: "I've worked with some great teams in the past; surely I can find a better situation than my current one."

Although there are studies of teams of employees that confirmed the met expectations-turnover linkage, expectations have been related to characteristics of the job itself (i.e., Pearson, 1995). Research contribution of the present study is made through the consideration of interpersonal variables (teamwork and social cohesion) as "expectations." A recent study found quality of team- 
member exchange (TMX) (described under satisfaction with Teamwork - below) to predict turnover and "[ameliorate] the negative effects of unmet expectations" (Major, Kozlowski, Chao, \& Gardner, 1995, p. 418). Met expectations in this study, again, referred solely to the job (role conflict, clarity, and acceptance), and turnover referred to leaving the organization, not the team (the focus of the present study).

Teamwork and social cohesion expectations (as a result of past experience) served as one of the independent variables predicting the importance of interpersonal reasons (teamwork/social cohesion) in past bid/assignment decisions (Hypothesis 1). It was hypothesized that higher expectations would lead to greater importance of these reasons. It is also important to emphasize Met Expectation's importance as a part of the Alternatives variable in Investment Theory. The following four sections review the literature and theoretical bases (where applicable) of the other variables included in the study: satisfaction with teamwork: social cohesion, social identity and relational demography; interpersonal orientation; and conflict tolerance. Satisfaction with Teamwork

A number of investigations have demonstrated the value of teams in the workplace. In a meta-analysis, Neuman, Edwards, and Raju (1989) found that team-building is one of 
the most effective ways to improve job satisfaction, while other researchers (Posner \& Randolph, 1979) found that teamwork can ameliorate some of the negative effects of role ambiguity. Job satisfaction has also been found to be strongly related to respect received from team members (Marriott, Sexton, \& Staley, 1994) and to a good match between group task (group $\mathrm{v}$. individual) and group outcomes (group V. individual) (Wageman, 1995).

The satisfaction described in the above-cited articles was general job satisfaction or facet satisfactions. Satisfaction with teamwork was not included in the studies, nor in most workplace studies of teamwork. One area in which teamwork satisfaction has been investigated more extensively is the study of athletic teams. Satisfaction with being a member of a team has been related to a "mastery climate," (Walling, Duda, \& Chi, 1993); general team satisfaction has been shown to strengthen the cohesionperformance relationship (Williams \& Hacker, 1982); and satisfaction with group goals has been predicted by group cohesion and group goals influence (Brawley, Carron, \& Widmeyer, 1993).

Although not focused directly on satisfaction, the study of team-member exchange (TMX) (Seers, 1989) is, perhaps, the most relevant research for the present study because it focuses on the relationships among team members. 
An extension of the 1970's research on leader-member exchange (Graen, Cashman, Ginsburgh, \& Schiemann, 1977), team-member exchange measured "the member"s perception of his or her willingness to assist other members, to share ideas and feedback and in turn, how readily information, help, and recognition are received from other members" (Seers, 1989, p. 119). Seers found TMX to contribute additional variance (beyond leader-member exchange) in the prediction of various types of job satisfaction. As mentioned in the previous section, Major, et al. (1995) found TMX to be a significant predictor of turnover. It also predicted organizational commitment and job satisfaction.

The present research expands the depth of literature regarding actual satisfaction with teamwork, and serves to combine/elaborate upon many of the above findings. Hypothesis 1's dependent variable was the importance of interpersonal reasons (teamwork/social cohesion) in past bid/assignment decisions. Four items (reasons) dealing with teamwork satisfaction comprised the teamwork portion of the dependent variable; reasons regarding satisfaction with social cohesion (discussed below) comprised the other portion of the dependent variable.) Expectations of teamwork was part of the first predictor variable in Hypothesis 1 (along with expectations of social cohesion). 
In a traditional turnover study, satisfaction with teamwork or social cohesion might affect an individual, but, perhaps, not enough to leave an organization. Such an individual might have found another way to withdraw from the group, such as social loafing (Latane', Williams, \& Harkins, 1979). In the present study, dissatisfaction with teamwork or social cohesion (or anything else) could more easily lead to turnover; the employee was not risking loss of any major components of their position.

Overall satisfaction with current bid/assignment was used as the independent variable for Hypothesis 2 a (the relationship between satisfaction and actual turnover). General job satisfaction was also assessed, to ensure that turnover was not simply due to overall job unhappiness; i.e., that there was not a significant difference in general job satisfaction between those that stayed and those that changed teams.

The next section discusses social cohesion, a key element of Hypothesis 1 . Social Cohesion, Social Identity, Relational Demography Eirefighter/paramedic teams can be considered action/negotiation teams, with work consisting of "brief performance events, often repeated under new conditions, requiring extended training and/or preparation" (Sundstrom, De Meuse, \& Futrel1, 1990, p. 125). Such teams are also 
characterized by stringent synchronization of duties, necessitating close relationships. The type of cohesion that enhances such work situations is increased by personal attractiveness of the group (Summers, Coffelt, \& Horton, 1988). Included in an early definition of work group cohesion is resistance to leaving on the part of the members (Seashore, 1954). Later research (i.e., Cartwright, 1968) included the need to consider restraints against leaving, and attractiveness of alternatives when studying such resistance.

The present study combines such research regarding cohesion and turnover. The terms cohesion and social cohesion have blended somewhat in the literature. For example, Seashore's (1954) operational definition of group cohesion focused on perception of the members as being part of a group, and preference to remain in the group, though questions were asked about "closeness" (p.41) between group members. Price and Mueller's (1986) three questions regarding integration (explained as often synonymous with cohesion) are more "social" in nature: discussion of personal problems, helping each other, and friendliness. Finally, Carron, Widmeyer, \& Brawley's (1985) cohesion scale included measures of both task integration and social integration. The present study's measure of cohesion was primarily social in nature, with questions regarding 
friendliness, personal interest, social activities, plus one general question regarding "sticking together".

The study's focus on the social component adds to several studies that have found employees with close friends at work to be less likely to leave their job (as cited in Iverson \& Roy, 1994, p. 37). It also adds to the small amount of research regarding groups that have a strong social component, and groups that live together. Much of the literature regarding the measurement of social cohesion is focused on athletic teams (i.e., Carron, Widmeyer, \& Brawley 1985; 1988). The later study found that group cohesion in athletic settings led to greater individual participation. It has also been demonstrated that the most cohesive units of the Army (A-team soldiers) reported greater individual satisfaction, and physical and psychological well-being (Manning \& Fullerton, 1988). Although military units live together, there is a large difference between such participants and those in the present study regarding the ability to carry forth turnover desires.

The importance of social cohesion in past bid/assignment decisions was assessed. As with teamwork satisfaction, this might be a variable considered in a traditional turnover study, but not one that would necessarily cause an employee to leave. Other variables 
(including the strength of alternatives) must usually be carefully considered (Cartwright, 1968). In the fire rescue workplace, employees who change stations lose nothing significant in terms of their job duties and benefits, and the importance of social cohesion in such decisions can be measured.

Two theories (social identity and relational demography) are helpful in understanding the importance of social cohesion in a team setting. "Social identity" is "that part of the individuals' self-concept which derives from their knowledge of their membership of a social group (or groups) together with the value and emotional significance of that membership" (Tajfel, 1981, p. 255). This identity is derived from the natural tendency to divide individuals into social categories; social categorization becomes the "key variable" (Tajfel, 1982, p. 22)

Social identity theory describes two further "steps". First, the social categories created lead to division of the world into "us" vs. "them." Next, in order to enhance selfesteem people are motivated to view their "ingroup" as superior to the "outgroup" (Anastasio, Bachman, Gaertner, \& Dovidio, 1997). Indeed, much of the research regarding social identity has focused on intergroup relations and behavior (Tajfel \& Turner, 1986; Bornewasser \& Bober, 1987). Interestingly, evidence has suggested that group cooperation 
and cohesion (the focus of the present research) are better explained as effects, rather than determinants, of ingroupoutgroup divisions (Turner \& Giles, 1981). It is not known whether strong ingroup-outgroup division occurred in the present sample; it would be somewhat difficult to assess because of the transient nature of the groups. However, the basic idea of social identity theory and its importance in group cohesion is quite clear.

Studies of organizational demography are also related to social cohesion among team members. Jackson, Brett, Sessa, Cooper, Julin and Peyronnin (1991) studied high-level executives team that differed in terms of seven demographic variables. Turnover rates were higher for more heterogeneous groups, both when assessed at the individual and group/team level. Wiersema and Bird (1993) reported similar, yet stronger, results in a non-U.S. team setting. These and similar projects are based, in part, upon Schneider's (1987) attraction-selection-attrition model. This model suggests that, through these three organizational processes, organizations become more homogeneous. This phenomenon is very relevant to the present research regarding team self-selection. Similarly, O'Reilly III, Caldwell, and Barnett (1989) found social integration to be a moderator for the relationship between tenure homogeneity and turnover. This moderating effect was not found, however, 
in regard to age homogeneity. Social integration was related to both age homogeneity and turnover, but the connection between the two variables was direct.

Research regarding Relational Demography has been undertaken to specify differences found at the individual level (Tsui \& Egan, 1992). Social identity theory, selfcategorization theory and the similarity-attraction paradigm (similar individuals are attracted to one another) (Byrne, 1971, as cited in Riordan \& Shore, 1997) are the bases for Relational Demography. Relational demography "proposes that individuals compare their own demographic characteristics with those of others in their social units to determine (similarity or dissimilarity)" (Riordan \& Shore, 1997, p. 342). These perceptions will, then, affect individual work-related attitudes and behaviors. It is important to realize that the noted differences are relative, and can be more or less important depending upon the particular social context.

In support of the theory, Tsui and O'Reilly III (1989) found that heterogeneous superior-subordinate dyads were associated with less effectiveness, less personal attraction on the superior's part, and more role ambiguity on the subordinate's part. In a study of 151 work units, lower levels of psychological attachment (commitment) to the organization were reported by more diverse groups (Tsui \& 
Egan, 1992). Thus, heterogeneity has been shown to affect both interpersonal relations and organizational function. It is the personal attraction basis of the above research that is particularly important for the present research. Each shift, the crew members had to agree upon such social/interpersonal issues as what to cook for dinner and how much to spend, what non-work issues are appropriate to discuss, and what television programs to watch (when time allows). It seems apparent that "liking one's teammates" would allow these everyday decisions, as well as those related to the job, to be much easier.

Thus, the present study allowed investigation, in an "intensively social" environment, of many of the abovereferenced social cohesion theories and ideas. The participants had the opportunity, if unhappy, to find another team that suited them better in terms of social interaction.

Hypothesis 1's dependent variable was the importance of interpersonal reasons (teamwork/social cohesion) in past bid/assignment decisions. Four items (reasons) dealing with social cohesion were included (satisfaction with teamwork comprised the other four items). Expectations of social cohesion was part of the first predictor variable in Hypothesis 1 (along with expectations of teamwork). 
The next section discusses interpersonal orientation, the second predictor variable in Hypothesis 1. Interpersonal Orientation

Closely tied to the above-cited research is that of interpersonal relationships at work, a topic that has been studied for many years. Van Zelst (1951) found that those high in interpersonal desirability were also much more positive about many aspects of their jobs. In 1952, Van Zelst took this research a step further into the study of teams, and found that regrouping based upon interpersonal desirability could increase job satisfaction. The study of teamwork, social identity, and relational demography are deeply rooted in interpersonal orientation (how important interpersonal relationships are to an individual). These forces would only be important to individuals for whom interpersonal relationships are a significant issue.

In addition to the study of similarity and liking in groups, many have studied individual differences in interpersonal orientation, and applied such research to team compatibility (Eisher, Macrosson, \& Walker, 1995; Johnson \& Arneson, 1991; Kubes, 1992). The present study contributes to the literature by providing more understanding about interpersonal orientation in a team setting, and examining interpersonal orientation's role in bid/assignment decisions. It was hypothesized that those higher in 
interpersonal orientation would place more importance on interpersonal reasons (teamwork/social cohesion) in past bid/assignment decisions. Interpersonal Orientation was, therefore, the second predictor in Hypothesis 1. (Expectations of teamwork and social cohesion was the first predictor.)

The next section discusses conflict tolerance, the first predictor in Hypothesis 1 and the focus of the preliminary study. Conflict Tolerance

Conflict can be understood from many different perspectives (Katz \& Kahn, 1978), but can still be defined to coincide with common usage: "two systems are in conflict when they interact directly in such a way that the actions of one tend to prevent or compel some outcome against the resistance of the other" (p. 613). Although high task interdependence (Dutton \& Walton, 1972 as cited in Dipboye, Smith, \& Howell, 1994) is considered just one cause of conflict, it seems to be the cause most directly derived from the classic definition stated above. The teams in the present study had a great deal of task interdependence, both formal and informal, and were, therefore, susceptible to intragroup conflict. The question asked was whether employees who were less tolerant of conflict placed more importance on interpersonal reasons (teamwork/social 
cohesion) in past bid/assignment decisions. Therefore, the focus was on the individual.

Much of the recent literature in the area of team conflict is focused on the differences between cognitive conflict (C-conflict) and affective conflict (A-conflict) (Amason, 1996: Amason, Thompson, Hochwarter, \& Harrison, 1995; Sessa, 1996). Though affective conflict stems from personality issues, the focus has been on teams, not individuals (the focus of the present study). Individual personality and predisposition have been acknowledged to be important in the arena of conflict (Katz \& Kahn, 1978). Classic research has found that "interaction oriented" group members are more concerned with maintaining harmonious relations (Bass \& Dunteman, 1963, p. 426). Eor example, union stewards' temperament affected union-management relations; those who were "friendly" sought to avoid hostility (Stagner, 1962, p. 356).

A review of the organizational conflict literature revealed the absence of scales to assess individual conflict tolerance. (In fact, only two studies were found regarding conflict tolerance. Both Eisenstein (1991) and von der Lippe (1986) studied conflict tolerance as a developmental issue.) Existing conflict scales measure respondents' view of how much conflict is apparent in the work group or workplace (Jehn, 1995; Rahim, 1983), and may include individual 
feelings about the conflict (Saavedra, Earley, \& Van Dyne, 1993). Development of a scale to assess conflict tolerance in the workplace is, therefore, a contribution to the literature regarding group processes. (Conflict Tolerance was the third independent variable hypothesized to predict importance of interpersonal reasons [teamwork/social cohesion] in past bid/assignment decisions. - Hypothesis 1) Preliminary Study (Conflict Tolerance Scale Development Study):

Twenty-eight conflict tolerance items were pilottested, with the goal of developing a brief instrument to be used in the focal study.

Focal Study

Following is the rationale that led to the focal study's hypotheses (based upon the research discussed). The dependent variable in Hypothesis 1 was the importance placed upon interpersonal reasons (teamwork/social cohesion) in past turnover (bid/assignment) decisions. Investment Model literature demonstrates that available alternatives are important in relationship decisions. Similarly, Met Expectations theory explains that individuals are more likely to leave an organization if their individual expectations were not realized. This led to the first predictor variable, expectations of teamwork and social cohesion. It was predicted that the more participants 
expected in terms of teamwork and social cohesion, the more likely they would be to make turnover decisions based upon satisfaction with these variables. In other words, if they did not expect to find better teamwork and social cohesion with another team, they would be more likely to stay with their current team.

The second predictor variable was interpersonal orientation. Research has shown that interpersonal attraction can be related to job satisfaction (which is, in turn, related to turnover). Furthermore, individual differences in interpersonal orientation have been found as important to team compatibility. This finding led to the inclusion of interpersonal orientation as a predictor variable. It was predicted that participants higher in interpersonal orientation (to whom "belonging" was important) would place greater importance on teamwork and social cohesion in assignment decisions.

Conflict tolerance was the third variable predicting importance of interpersonal reasons in bid/assignment decisions. High task interdependence (as in the present study) has been shown to promote increased conflict and/or make conflict a more salient issue. Also, similar to interpersonal orientation, research has shown there to be individual differences in the area of conflict and desire for harmonious relationships. Therefore, it was assumed 
that conflict management would be important in this workplace; and it was predicted that those lower in conflict tolerance would be more likely to base their assignment decisions on interpersonal factors. Hypothesis 1:

A model of "Intra-Organizational Turnover" was proposed. The dependent variable was the Importance of Interpersonal Reasons (Teamwork/Social Cohesion) in Past Bid/Assignment Decisions. The following were hypothesized as predictors: Expectations of Teamwork and Social Cohesion, Interpersonal Orientation, and Conflict Tolerance. The model is illustrated below:

Importance of Expectations (Teamwork, Social Cohesion)-- Interpersonal
Interpersonal Orientation-.-
Conflict Tolerance-.- Reasons

Assignment Decisions

It was predicted that higher expectations, higher interpersonal orientation, and lower conflict tolerance would predict greater importance of interpersonal reasons (teamwork/social cohesion) in past bid/assignment decisions. Participants were asked about their general past use of interpersonal reasons (teamwork/social cohesion) in 
bid/assignment decisions, because one overriding factor (such as the desire to move from a fire suppression assignment to a rescue assignment) could cause an individual's turnover during a single bid period.

Participants were also surveyed regarding whether they were changing teams/assignments in the current bid cycle. Based upon the strong recognized relationship between satisfaction and turnover, the next hypothesis was formed. Hypothesis 2a: It was hypothesized that those who were changing teams/assignments (answering "Yes" to Turnover Decision) would report lower Current Bid/Assignment Satisfaction.

Because these employees have had many past opportunities to change teams, an item regarding past turnover frequency was included. It was expected that there would be a relationship demonstrated between those who changed teams frequently and those that change teams in a given bid cycle. In other words, it was predicted that there were some individuals that were more predisposed (more likely) to change teams. Hypothesis 2b: It was hypothesized that those who were changing teams/assignments (answering "Yes" to Turnover Decision) would report higher Past Individual Turnover Frequency . 


\section{CONFLICT TOLERANCE SCALE DEVELOPMENT STUDY}

METHOD

Participants

Participants were 147 students in three undergraduate psychology courses. Eighty-one (55.1\%) of the participants had worked full-time, 58 (39.5\%) had worked part-time, 2 (1.4\%) had never worked; and 6 (4.1\%) did not respond to this item.

Materials

A 28-item Conflict Tolerance questionnaire was developed for this study. The questionnaire specifically focused on individual capability to tolerate conflict among co-workers. The questionnaire is shown in Appendix A. A 5point likert-type scale, common in attitudinal research (Anastasi \& Urbina, 1997) was utilized.

In order to develop items, scales measuring workplace conflict were consulted. A first-person statement format was utilized (similar to the situation-specific attitudinal items in Saavedra, Earley, \& Van Dyne, 1993) to elicit as much personal feeling as possible. Basic ideas and terminology such as "harmony" (Rahim, 1983) and "friction" (Jehn, 1995) were useful for item development.

The items developed represented several broad attitudinal categories of conflict tolerance. These 
categories seemed to represent a wide range of feelings that underlie tolerance or intolerance for workplace conflict. The categories are as follows: acceptance and expectancy of conflict tolerance, perceived benefits of conflict tolerance, interference of conflict with work and home life, attitude toward those who are not tolerant, avoidance of conflict, and importance of harmony.

Procedure

The students were told briefly about the dissertation topic, and the need to "pilot test" items for a new scale. Their individual participation was solicited, but the voluntary nature of the study was made clear. The participants took as much time as needed to complete the questionnaire. 


\section{$\underline{\text { RESULTS }}$}

Table 1 shows the reliability analysis (coefficient alpha) of the 28 Conflict Tolerance items that were pilot tested in the preliminary study. Overall alpha for the scale was .75 . The inter-item total correlations ranged from .05 (item number 7) to .48 (item number 12). Utilizing a cut-off correlation of .3 (a "natural break") resulted in the initial choice of a seemingly reasonable number of items: fourteen. One additional item (\#8) was deleted because of its similarity to another of the chosen fourteen items. Another additional item (\#3) was deleted because, upon further consideration, it did not seem to be a "face valid" indicator of individual conflict tolerance. The twelve final items are marked with an asterik in Table 1. Table 2 shows the reliability analysis (coefficient alpha) for the twelve selected items. Alpha was .75, and the item-total correlations ranged from .26 to .53 .

A frequency table of Conflict Tolerance scores (utilizing the twelve selected items) is displayed in Table 3. The summary statistics (including a mean of 1.78 and a median of 1.75 ) and perusal of the frequencies show a distribution that approximates normality. 
CONFLICT TOLERANCE SCALE RELIABILITY:

28 PILOT-TESTED ITEMS

Reliability Coefficients: Alpha:

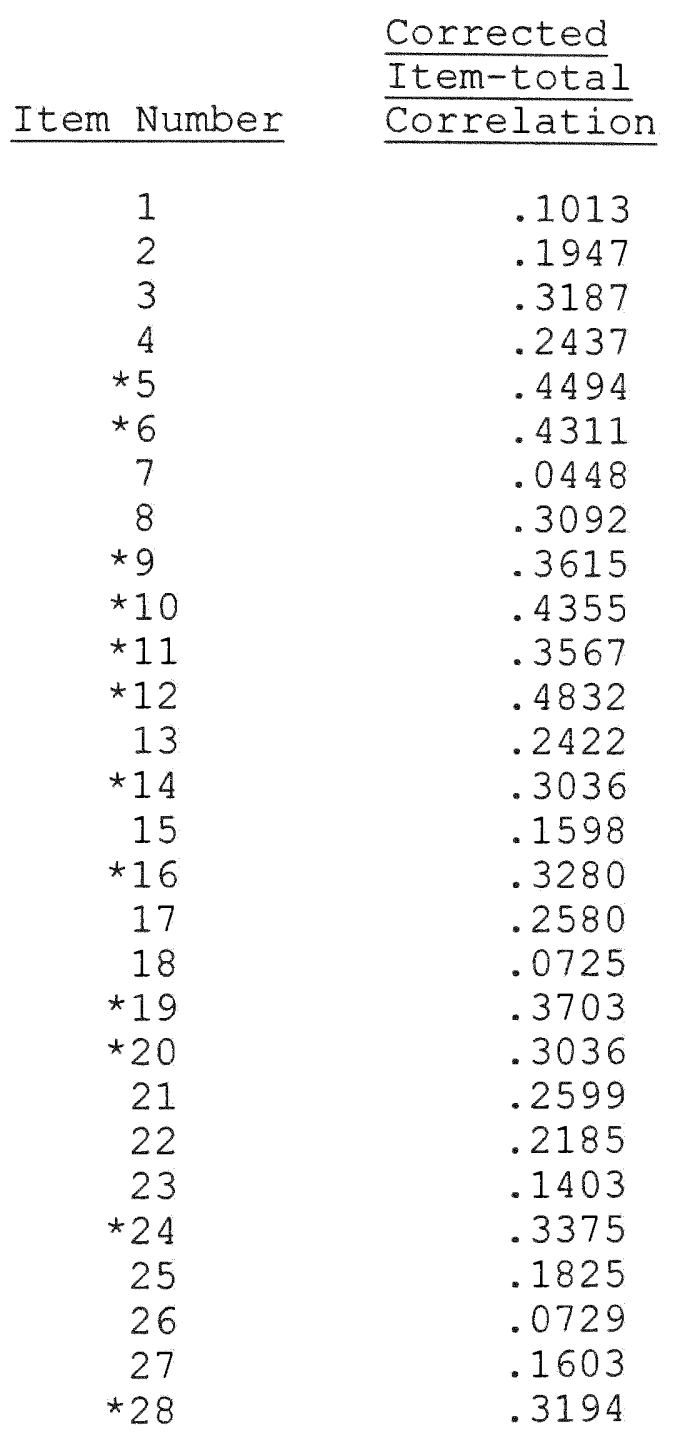

28 items

.7477 $\frac{\text { Alpha if }}{\text { Item Deleted }}$

.7504

.7454

.7382

.7421

.7284

.7295

.7529

.7380

.7343

.7314

.7351

.7266

.7421

.7384

.7466

.7369

.7414

.7517

.7347

.7384

.7414

.7442

.7476

.7372

.7452

.7519

.7478

.7377

* Selected items 


\section{TABLE 2}

CONELICT TOLERANCE SCALE RELIABILITY:

12 SELECTED ITEMS

Reliability Coefficients: Alpha:

\begin{tabular}{cc} 
Item Number & $\frac{\text { Corrected }}{\text { Item-total }}$ \\
\hline 5 & $\frac{.4945}{\text { Correlation }}$ \\
6 & .4978 \\
9 & .3287 \\
10 & .5292 \\
11 & .4222 \\
12 & .4872 \\
14 & .2591 \\
16 & .2632 \\
19 & .2644 \\
20 & .4057 \\
24 & .2821 \\
28 & .3153
\end{tabular}

12 items

.7452 
FREQUENCY TABLE -

CONELICT TOLERANCE SCORES

PILOT TEST - 12 SELECTED ITEMS

\begin{tabular}{|c|c|c|c|}
\hline Value & Erequency & $\frac{\text { Valid }}{\text { Percent }}$ & $\frac{\text { Cumulative }}{\text { Percent }}$ \\
\hline .67 & 1 & .7 & .7 \\
\hline .75 & 1 & .7 & 1.4 \\
\hline .83 & 2 & 1.4 & 2.9 \\
\hline .92 & 1 & .7 & 3.6 \\
\hline 1.00 & 8 & 5.7 & 9.3 \\
\hline 1.08 & 2 & 1.4 & 10.7 \\
\hline 1.17 & 5 & 3.6 & 14.3 \\
\hline 1.25 & 6 & 4.3 & 18.6 \\
\hline 1.33 & 4 & 2.9 & 21.4 \\
\hline 1.42 & 7 & 5.0 & 26.4 \\
\hline 1.50 & 15 & 10.7 & 37.1 \\
\hline 1.58 & 5 & 3.6 & 40.7 \\
\hline 1.67 & 4 & 2.9 & 43.6 \\
\hline 1.75 & 11 & 7.9 & 51.4 \\
\hline 1.83 & 12 & 8.6 & 60.0 \\
\hline 1.92 & 6 & 4.3 & 64.3 \\
\hline 2.00 & 10 & 7.1 & 71.4 \\
\hline 2.08 & 7 & 5.0 & 76.4 \\
\hline 2.17 & 6 & 4.3 & 80.7 \\
\hline 2.25 & 3 & 2.1 & 82.9 \\
\hline 2.33 & 2 & 1.4 & 84.3 \\
\hline 2.42 & 5 & 3.6 & 87.9 \\
\hline 2.50 & 6 & 4.3 & 92.1 \\
\hline 2.58 & 4 & 2.9 & 95.0 \\
\hline 2.67 & 3 & 2.1 & 97.1 \\
\hline 2.75 & 1 & .7 & 97.9 \\
\hline 3.00 & 1 & .7 & 98.6 \\
\hline 3.25 & 1 & .7 & 99.3 \\
\hline 3.58 & 1 & .7 & 100.0 \\
\hline$\cdot$ & 7 & Missing & \\
\hline Total & 147 & 100.0 & \\
\hline Mean & 1.783 & Minimum & .667 \\
\hline Median & 1.750 & Maximum & 3.583 \\
\hline Std.Dev. & .528 & Range & 2.917 \\
\hline Variance & .279 & & \\
\hline Std.Error & .045 & & \\
\hline
\end{tabular}




\section{DISCUSSION}

Although the sample did consist of college students (a common reason for criticism of psychological research), 55\% of these students had full-time work experience, and an additional 39\% had part-time work experience. Furthermore, the study examined the psychometric properties of a general work attitude, rather than trying to make an inference about behavior in a work setting.

The scale derived from the selected items has good internal consistency (alpha $=.75)$. Therefore, there is a good deal of "interrelatedness" (or "low uniqueness") among the items (Cortina, 1993, p. 102). Cortina further explains, however, that coefficient alpha is a function of the average correlation among items, and can be large in spite of a wide range of item intercorrelations (a lack of unidimensionality or homogeneity). In fact, factor analysis conducted with the sample does not reveal a single underlying factor. Nevertheless, the use of conflict tolerance in the focal study is successful. It contributes to the equation predicting the importance of interpersonal reasons in past bid/assignment decisions, and is negatively correlated with interpersonal orientation. (See Results below)

Further research regarding the conflict tolerance construct, and refinement of the conflict tolerance scale, 
is suggested. A conflict tolerance scale could be used for many purposes, such as organizational development (including team-building) and individual career planning/development. Within the research arena, it can contribute to our continued understanding of individual differences in the workplace. 
FOCAL STUDY

METHOD

Participants

Participants were firefighter/paramedics and firefighter/emergency medical technicians employed by a large fire rescue department in the southeastern United States. Approximately 900 questionnaires were distributed, and 446 were returned (of which five were unusable, and fourteen were incomplete). It is not known exactly how many individuals were actually given, or made aware of, the questionnaire (see Procedure below). The response rate was, therefore, at least $49.6 \%$ (based upon the 900 questionnaires distributed). Questionnaires were distributed the same week that the "bids closed" (turnover decisions were finalized). Of the 358 participants who chose to include their age, the mean was 41.6 years and the median was 43 years. The range was from 20 to 56 years of age. Of those (368 participants) who included their gender, 92\% were male and 8\% were female. Of those (332) who included their ethnic background, 65\% classified themselves as Anglo or Caucasian, 10\% classified themselves as Black or African-American, 23\% classified themselves as Hispanic, and $2 \%$ classified themselves as being of another ethnic background. Of those (373) that included their rank, 63응 were firefighters, $24 \%$ were lieutenants, and 13\% were captains. Of those (367) 
that included their tenure with the department, the mean was 15.2 years and the median was 16 years. The range was from 6 months to 36.5 years.

All participants worked in Operations divisions of the department, handling the day-to-day responses generated through the 911 emergency system. Those handling primarily fire suppression alarms worked in teams of four, while those primarily handling emergency medical calls worked in teams of three.

Materials

The questionnaire utilized in the focal study is shown in Appendix B. The scales are as follows:

Questionnaire Page 1 - Teamwork Expectations

Questionnaire Page 2 - Social Cohesion Expectations, Job Satisfaction, and Interpersonal Orientation Questionnaire Page 3 - Conflict Tolerance, Reasons for Bid/Assignment Decisions Questionnaire Page 4 - Current Bid/Assignment Satisfaction, Miscellaneous and Demographic Questions

The following section details references used for the scales, as well as the rationale for the items chosen and/or created.

Teamwork Expectations, Teamwork items in Reasons for Bid/ Assignment Decisions, and Teamwork items in Current 
Bid/Assignment Satisfaction - Modifications of Team-Member Exchange Quality instrument (Seers, 1989), plus one modified item from Individual Satisfaction questionnaire (Hand, Estafen, \& Sims, Jr., 1975). The Team-Member Exchange Quality scale was the only scale found that could, with slight modification, be used to assess teamwork expectations, teamwork as a reason to choose a position, and current teamwork satisfaction. It also proved to work very well in this study. Several of the most appropriate items for the fire rescue workplace were chosen. For instance, these employees do not have typical problem-solving meetings, so items regarding team meetings were not chosen. Also, although the teams solve problems every day, it is done very quickly. Therefore, items regarding step-by-step problem-solving were not used. Modifications were made for these type of reasons, as well as to change the format into expectations, or measures of importance, rather than regular statements. An item regarding team accomplishment (Hand, et al., 1975) seemed appropriate, but was not a part of the Team-Member Exchange scale.

Social Cohesion Expectations, Social Cohesion items in Reasons for Bid/Assignment Decisions, and Social Cohesion items in Current Bid/Assignment Satisfaction - Modified items from Price \& Mueller, 1986 and Seashore, 1954, plus additional items created for the study. The two cited 
studies provided general concepts of social cohesion such as friendliness, "taking a personal interest," and "sticking together". Half of the items, however, were created because they were rather specific to the setting. These items dealt with sharing of meals, holidays, non-work activities, etc. Job Satisfaction - Affective Responses portion of the Job Diagnostic Survey (Hackman \& Oldham, 1975). The JDS was utilized because of its strong history as a measure of job satisfaction. The Affective Responses portion provided a brief scale that solely measured participants' feelings about their job.

Interpersonal Orientation - Eight items from Inclusion scales of FIRO-B (Fundamental Interpersonal Relations Orientation (Schutz, 1958). The EIRO-B was chosen for its well-documented history, as well as its past usage in team research (e.g., Eisher, Macrosson, \& Walker, 1995). The Inclusion scale, which measures need for "belongingness" and affection, was the most appropriate for this research. The study attempted to measure how much the participants liked/needed to be with others, not the need for control or Affection (the other two scales of the FIRO-B). Conflict Tolerance - 12-item scale created for the study; derived from 28 pilot-tested items (described in conflict Tolerance Scale Development Study). 
Other Reasons for Bid/Assignment Decisions - Created for the study. Items were generated through discussions with Operations personnel, and the author's experience as an employee of the department.

Other Facets of Current Bid/Assignment Satisfaction Created for the study. Items were generated through discussions with Operations personnel, and the author's experience as an employee of the department. Turnover Items - Whether or not employee was changing their bid/assignment; how often employee changes bids/assignments; length of time employee had worked with their current team. Miscellaneous and Demographic Items (optional) - Current assignment; how far employee lives from work; length of employment with department; length of employment in total; rank; age; gender; ethnicity; name.

Procedure

Distribution

The individual questionnaires included an introductory/explanatory letter as part of the first page (Appendix B). Questionnaires were sent to 42 fire rescue stations. Initial distribution was made through a presentation at the weekly division-level Operations staff meeting. Within the next few days, the chiefs attending this meeting met with the Battalion Chiefs under their command to ask for their cooperation, and ensure delivery of 
the questionnaires to the stations in their respective areas.

Two envelopes were prepared for each station. One contained blank questionnaires with letter-sized envelopes attached (for placement of completed questionnaires). A letter was taped to the outside of the envelope explaining the questionnaire and collection method to each station Captain (the officer responsible for "cross-shift" assignments). The letter asked the station Captains for their assistance, and explained that they would be called by telephone to have any questions answered. The second envelope was a large "taped" and "stapled" collection envelope. It was created to allow participants a somewhat secure place in which to place their sealed envelopes. Telephone Notification and Solicitation of Response

Each of the 42 Station Captains was called at least once to thank them for their assistance, and answer any questions. In addition, each station was called at least two additional times to ensure that the questionnaires were passed along to all three shifts, to answer any questions, to "personally" request participation from as many individuals as possible, and to explain that this was solely an academic research project. Because this last issue was of concern to many people, bright neon flyers were sent to all stations reiterating this point. 
Collection

Personal visits were made to most stations, either once or twice, to collect completed surveys and personally ask for additional participation. The blank surveys and collection envelopes were left at the stations so that additional questionnaires could be collected. Four weeks after the distribution began, all materials were retrieved from the stations (either through personal visits, departmental messenger, or other voluntary messenger). Individual responses were received through inter-office mail for approximately one additional month.

Because the responses were captured directly on the questionnaires (rather than a "bubble" scan sheet), the data was entered into sPSS "by hand." 
A Principal Components Analysis of Reasons for Bid/Assignment Decisions is displayed in Table 4. Varimax rotation simplified the items into two factors. The correlations of items 12-19 (regarding teamwork and social cohesion) with Factor 1 ranged from .70 to .90. In contrast, ten of the other eleven items had correlations of less than .24 with factor 1 . The correlation of item number 8 (regarding supervision) with Factor 1 was .43 .

Reliability analyses for the scales contributing to the focal study are shown in Table 5. (Teamwork Expectations and Social Cohesion Expectations were combined in order to test Hypothesis 1 (below). Coefficient alpha ranged from .71 (Conflict Tolerance) to .96 (Interpersonal Factors [Teamwork/Social Cohesion] in Current Bid/Assignment Satisfaction). Seven items in the final Conflict Tolerance scale were recoded (in reverse): item numbers $1,2,3,4,5$, 10, and 12 (item numbers were not included on the questionnaire).

Table 6 displays the descriptive statistics and correlation matrix for the variables used in the focal study. All of the correlations (other than four involving Conflict Tolerance) were significant, or nearly significant. 

$\frac{\text { EACTOR ANALYSIS (PRINCIPAL COMPONENTS) }}{\text { REASONS FOR BID/ASSIGNMENT DECISIONS }}$

Rotated Factor Matrix (Varimax)

Item Number

1: Geographical

2: Physical Facility

3: Population served

4: Types of calls

5: Wanting shift change

6: Station activity

7: Wanting diff. assign.

8: Supervisors

9: Hospitals

10: Pay incentives

11: Change of pace

12: Co-workers: friendly

13: Co-workers: interest

14: Co-workers: social

15: Co-workers: together

16:Team cooperation

17: Team appreciation

18: Team communication

19: Team compromise
Factor 1

$-.06980$

.04603

.05171

.05490

.07876

$-.06298$

.13289

.42938

.23419

.18875

.14218

.73243

.70372

.80164

.84894

.90172

.87321

.86444

.86609
Factor 2

.58080

.63968

.59626

.55287

.48928

.49678

.35449

.36544

.53444

.49415

.44998

.19377

.18554

.10101

.05900

.02189

.06180

.11229

.06133 
$\underline{\text { Scale }}$

Teamwork Expectations

Social Cohesion

Expectations

Job Satisfaction

Interpersonal

orientation

Conflict Tolerance

Importance of

Interpersonal Reasons

(Teamwork/Social Cohesion)

in Bid/Assignment

Decisions

Current Bid/Assignment

Satisfaction - Interpersonal

Factors

Overall Current

Bid/Assignment

Satisfaction
Alpha

.95

.91

10

.77

7

.88

8

.71

12

.94

8

$$
.96
$$

8

.91

19 


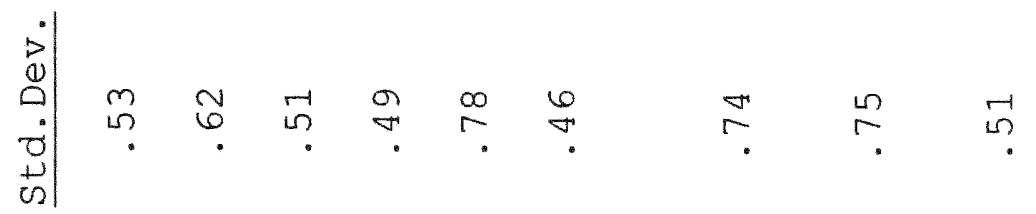

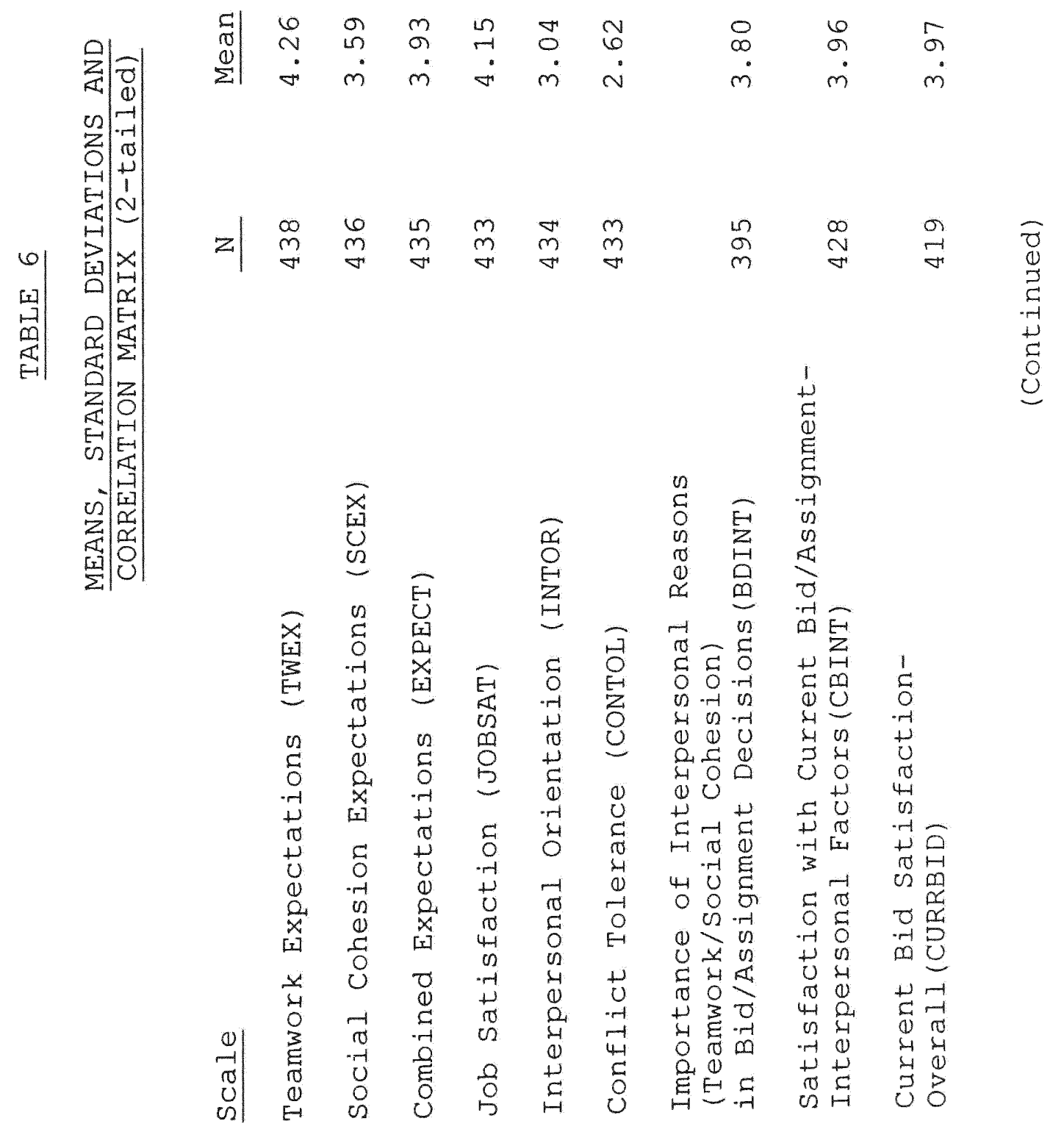




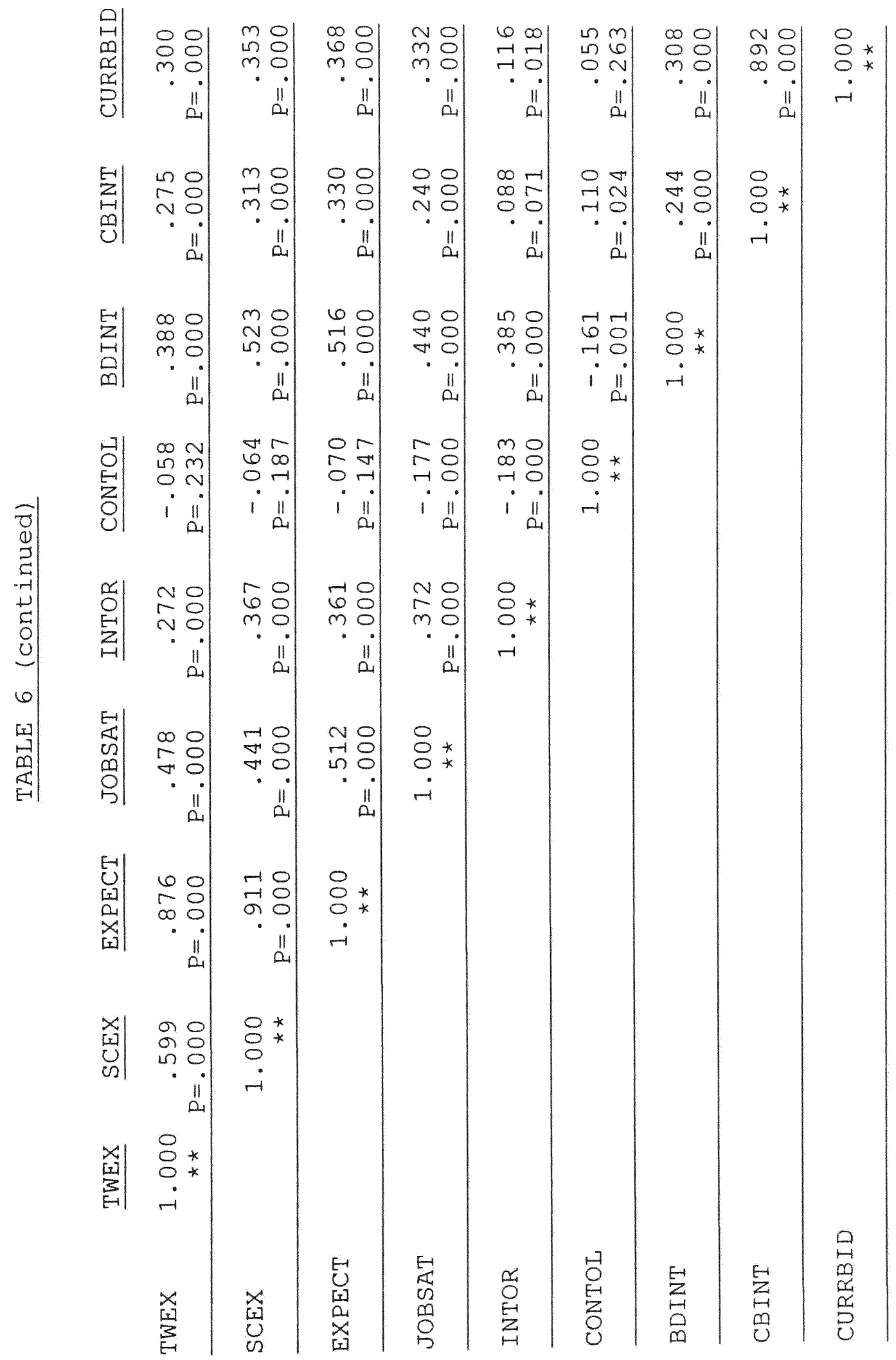


Hypothesis 1:

Tables 7 and 8 are tests of Hypothesis 1: that the importance of interpersonal reasons (teamwork/social cohesion) in past bid/assignment decisions would be greater for those with higher expectations regarding teamwork and social cohesion, higher in interpersonal orientation, and lower in conflict tolerance. The hypothesis was supported. Table 7 shows that all three independent variables did significantly contribute to the equation (Mult. $\underline{R}=.57$; Adj. $\underline{R}$ Squared $=.31$ ).

To a lesser extent, interpersonal orientation and conflict tolerance predicted importance of "other reasons" in past bid/assignment decisions (Mult. $\underline{R}=.27$; Adj. $\underline{R}$ Squared $=.07)($ Table 8$)$. In a test for difference between the two equations' multiple correlation coefficients, $\underline{T}=13.6(\underline{\mathrm{df}}=385, \underline{\mathrm{p}}<.001)$. Therefore, the first equation (predicting importance of interpersonal reasons in past bid/assignment decisions) reflected a stronger relationship between the independent variables and the dependent variable.

The size of $\underline{N}$ for both equations (388 and 386) was substantially higher than the 76 required to detect a medium effect size at the .05 level, with power of .80 , for Multiple $\underline{R}$ with 3 independent variables. The number of participants, was, in fact, closer to the 547 needed to 
MULTIPLE REGRESSION PREDICTING IMPORTANCE OF INTERPERSONAL REASONS (TEAMWORK/SOCIAL COHESION) IN BID/ASSIGNMENT DECISIONS

Dependent Variable: Importance of Interpersonal Reasons in Bid/Assignment Decisions

Method:

Stepwise

$N=388$

Variable(s) Entered

Step 1

Step 2

Step 3
Expectations

Interpersonal orient.

Conflict Tolerance
Mult.R Adj.R Squared

.5155

.5580

.5652
.2638

.3078

.3141

Final Equation

Variable

Expectations

Interpesonal Orient.

Conflict Tolerance

(Constant)

\begin{tabular}{|c|c|c|c|c|}
\hline$B$ & SE B & Beta & $T$ & Sig. T \\
\hline .6234 & .0650 & .4325 & 9.59 & .0000 \\
\hline .2025 & .0436 & .2123 & 4.64 & .0000 \\
\hline 1487 & .0695 & -.0915 & -2.14 & .0330 \\
\hline .1251 & .3184 & & 3.53 & .0005 \\
\hline
\end{tabular}


MULTIPLE REGRESSION PREDICTING IMPORTANCE OF OTHER (THAN INTERPERSONAL) REASONS IN BID/ASSIGNMENT DECISIONS

Dependent Variable: Importance of Other Reasons in Bid/Assignment Decisions

Method:

Stepwise

$N=386$

Variable(s) Entered Mult.R Adj.R Squared

Step 1 Interpersonal Orient. $\quad .2486 \quad .0594$

$\begin{array}{lll}\text { Step } 2 \text { Conflict Tolerance } & .2696 & .0679\end{array}$

Final Equation

Variable

B SE B Beta T Sig. T

Interpesonal Orient. $\begin{array}{llllll}.1591 & .0347 & .2292 & 4.58 & .0000\end{array}$

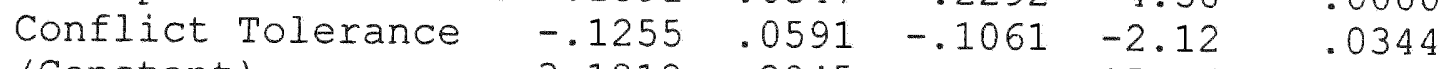

(Constant)

$3.1818 \quad .2045$

15.56

.0000

Variable not in the Equation

Variable Beta in Partial Min. Toler. T Sig. T

$\begin{array}{llllll}\text { Expectations } & .0948 & .0918 & .8448 & 1.81 & .0719\end{array}$ 
detect a small effect size (same alpha and power level). (Cohen, 1992)

Newer employees (with less than two years of tenure) were not used for this analysis. For possible exploratory purposes, they were asked to predict the importance they would place on reasons for bid/assignment decisions. In reality, however, they had not had the opportunity to make many, if any, turnover decisions. Hypothesis 2a:

Table 9 shows the Analysis of Variance conducted to determine if those who left their teams/assignments were, indeed, less satisfied with their current bid/assignment. The hypothesis was supported $(\underline{E}=19.43, \mathrm{df}=1,376$, $\underline{p}<.0001$ ). As displayed, 81 individuals (21\%) did change assignments. Mean Satisfaction scores for those who changed assignments was 3.75. Eor those who stayed with their team/assignment, mean Satisfaction was 4.02. 95\% Confidence intervals for these means are also shown. (In contrast to the above ANOVA, it was found that General Job Satisfaction was not related to Turnover: $\underline{E}=.26$, df $=1,385, \underline{p}=.61$ ).

The size of the "Yes" group (81) exceeds the $N$ of 64 needed (for each of the 2 groups) to detect a medium effect size at the .05 level, with power of .80 (for an ANOVA with 2 groups) (Cohen, 1992). 
ANALYSIS OF VARIANCE CURRENT BID/ASSIGNMENT SATISFACTION BY TURNOVER DECISION (YES/NO)

$\begin{array}{lcccccc}\text { Source } & \underline{D E} & \begin{array}{l}\text { Sum of } \\ \text { Squares }\end{array} & \begin{array}{l}\text { Mean } \\ \text { Squares }\end{array} & \text { F } & \text { F Prob. } \\ \begin{array}{l}\text { Between } \\ \text { Groups }\end{array} & 1 & 4.83 & 4.83 & 19.43 & .0000 \\ \begin{array}{l}\text { Within } \\ \text { Groups }\end{array} & 376 & 93.46 & .25 & & \\ \text { Total } & 377 & 98.29 & & & & \end{array}$

Group Count Mean Std.Dev. Std.Error 95\% Conf.Int.for Mean $\begin{array}{llllllll}\text { Yes } & 81 & 3.75 & .54 & .06 & 3.63 & \text { to } & 3.87\end{array}$

No $\quad \begin{array}{lllllll}297 & 4.02 & .49 & .03 & 3.97 & \text { to } & 4.08\end{array}$

\begin{tabular}{|c|c|c|c|}
\hline Total 378 & 3.96 & .51 & .03 \\
\hline
\end{tabular}

$\begin{array}{lcc}\text { Group } & \text { Minimum } & \text { Maximum } \\ \text { Yes } & 2.21 & 4.89 \\ \text { No } & 2.16 & 5.00\end{array}$


As with the multiple regression analyses, new employees were not included in these analyses. Because of rotation requirements for training purposes, most did not have a choice in their assignment.

\section{Discriminant Analysis: Prediction of Turnover by Current} Bid/Assignment Satisfaction Items (Addendum to Hypothesis 2a)

As an addition to the turnover decision examined in Hypotheses 2a, a discriminant analysis was performed to determine which items from the Current Bid/Assignment Satisfaction scale best predicted turnover. The results are displayed in Table 10. Four items were included in a stepwise discriminant function: Satisfaction with cooperation and help team members offer each other; Satisfaction with geographical location; Satisfaction with pay incentives; and Satisfaction with assignment in general (included as a counterpart to wanting a "fresh assignment," or "change of pace" in reasons for turnover decisions).

The canonical correlation between the predictors and turnover group membership ("Yes" or "No") was.30. ChiSquare $=36.5(\mathrm{df}=4)$ showed the relationship to be significant $(\mathrm{p}<.0001)$. Subsequent analysis found that satisfaction with geographical location was related to distance of home to work (Contingency coefficient $=.34$; 
$N=378$

\begin{tabular}{|c|c|c|c|}
\hline Step & Entered & $\begin{array}{l}\text { Wilks' } \\
\text { Lambda }\end{array}$ & Sig. \\
\hline 1 & $\begin{array}{l}\text { Item 16: Satisfaction with } \\
\text { cooperation and help team } \\
\text { members offer each other }\end{array}$ & .9482 & .0000 \\
\hline 2 & $\begin{array}{l}\text { Item 01: Satisfaction with } \\
\text { geographical location } \\
\text { of station }\end{array}$ & .9289 & .0000 \\
\hline 3 & $\begin{array}{l}\text { Item 10: Satisfaction } \\
\text { with pay incentives }\end{array}$ & .9172 & .0000 \\
\hline 4 & $\begin{array}{l}\text { Item 11: Satisfaction } \\
\text { with assignment in } \\
\text { general }\end{array}$ & .9071 & .0000 \\
\hline
\end{tabular}

Canonical Discriminant Functions \% of Cum. Canon. After Wilks ChiEcn Eigenvalue Variance $\frac{\circ}{6}$ Corr. $\frac{\text { Fcn }}{0} \frac{\text { Lambda }}{.91} 3 \frac{\mathrm{Sq}}{6.5} \frac{\mathrm{df}}{4} \frac{\mathrm{Sig}}{.0000}$ $1.1024 \quad 100 \quad 100 \quad .30$

Standardized canonical discriminant function coefficients Func 1

Item 01:

.38

Item 10:

$-.48$

Item 11

Item 16:

.43

.56 
TABLE 10 (cont.)

Crosstabulations/Chi Square

Contingency Coefficients of Item 10 with

Item 1, Item 11, Item 16, and Turnover

Item 10

Item 1

.25

$(p=.03)$

Item 11

.50

$(p<.00001)$

Item 16

.37

$(p<.00001)$

Turnover

.07

$(p=.73)$ 
$\underline{\mathrm{df}}=16, \underline{\mathrm{p}}=.003)$. Those who lived closer to their station were more satisfied with the station's geographical location.

The second page of Table 10 displays the relationship of Item 10 to Items 1, 11, 16, and turnover decision. Item 10 (satisfaction with pay incentives) did not correlate with Turnover (contingency coefficient $=.07, \mathrm{p}=.73$ ), although it was part of the discriminant function. (See Discussion) Although stepwise discriminant analyses resemble regression equations, the mathematical properties are really analogous to "a MANOVA turned around" (Tabachnick \& Fidell, 1989, p. 505). Therefore, the Analysis of Variance sample size listing for power analysis is applicable. The size of the "Yes" group (78) exceeded the $\mathrm{N}$ of 64 needed (for each of the 2 groups) to detect a medium effect size at the .05 level, with power of .80 (Cohen, 1992). Hypothesis $2 \mathrm{~b}$ :

The hypothesized relationship between higher individual turnover frequency and current turnover was supported. The 2-way Chi-Square analysis (Table 11) found the Contingency Coefficient to be $.40 \quad(\mathrm{p}<.0001)$. Therefore, those who are currently changing teams reported more frequent turnover in the past. $\mathrm{N}$ of 375 for this analysis far exceeds the 143 needed to detect a medium effect size in a Chi-Square 
TABLE 11

CROSSTABULATIONS/CHI-SQUARE INDIVIDUAL TURNOVER FREQUENCY AND TURNOVER DECISION (YES/NO)

Turnover Count (Exp.Value) Turnover Decision

Erequency

Most often 1 2

4

5

Least often 6

1 (Yes) 2 (No) Row Total

$12(2.9) \quad 2(11.1): 14(3.7 \%)$ $19(7.9) \quad 19(30.1): 38(10.1 \%)$ $20(19.3) \quad 73(73.7): 93(24.8 \%)$ $12(13.7) \quad 54(52.3): 66(17.6 \%)$ $1(6.7) \quad 31(25.3): 32(8.5 \%)$ $14(27.5) \quad 118(104.5): 132(35.2 \%)$ Column Total $78(20.8 \%) 297(79.2 \%) \quad 375(100.0 \%)$

\begin{tabular}{lccc} 
Chi-Square & Value & DF & Significance \\
Pearson & 70.18 & 5 & .0000 \\
Likelihood Ratio & 61.71 & 5 & .0000 \\
Mantel-Haenszel test & 45.39 & 1 & .0000 \\
$\quad$ for linear assoc. & & & \\
\hdashline Statistic & $\frac{\text { Value }}{.40}$ & \\
Contingency Coeff. & & \\
* Pearson chi-square probability &
\end{tabular}


analysis $(\underline{\mathrm{d} f}=5)$, at the .05 level, with power $=.80$ (Cohen, 1992).

Category \#7 of the turnover frequency item (those who rarely or never change teams/assignments because they' re new employees) was removed. This category was included in the questionnaire, to differentiate between those who truly change assignments infrequently from new employees who simply have not held their job long enough to do so. This differentiation was needed because the demographic information (including department tenure) was optional. Exploratory Analyses

There were several demographic findings in regard to importance of interpersonal reasons (teamwork/social cohesion) in past bid/assignment decisions. These factors were used to a greater extent by younger employees $(\underline{r}=-.22, \underline{p}<.001)$; by newer employees $(\underline{r}=-.16$, $\underline{p}=.003)$; by women $(\underline{E}=6.15,1,332, \underline{p}=.0136 ; \underline{r}=.13$, $\underline{p}<.01)$; by firefighters compared to lieutenants (the first supervisory rank) $(\underline{E}=6.37,2,335, \underline{p}=.0019$, followed by a Scheffe' post-hoc test); and by those of Hispanic descent compared to those who classified themselves as Anglo or Caucasian $(\underline{E}=6.37,2,291, \underline{p}=.002$, followed by a Scheffe' post-hoc test). Actual turnover was greater among younger employees $(\underline{E}=21.7,1,326, \underline{p}<.0001$; 
$\underline{r}=.25, \underline{\mathrm{e}}<.0001)$ and newer employees $(\underline{\mathrm{F}}=24.26,1,337$, $\underline{p}<.0001 ; \underline{r}=.26, \underline{p}<.001)$. 


\section{DISCUSSION}

Factor Analysis (Principal Components) - Reasons for Bid/Assignment Decisions (Table 4)

The correlations of Factor 2 with items 1-11 ranged from .35 to .64 , while the teamwork and social cohesion items (12-19) correlations with Factor 2 were all less than .2. The Principal Components Analysis was, therefore, successful. Factor 1 displayed higher correlations with the interpersonal reasons for turnover decisions, and Factor 2 displayed higher correlations with the "other" reasons. The fact that satisfaction with supervision correlated fairly well with the "interpersonal factor" is not too troubling. Although superior-subordinate relationships are focused on the work product, they are, of course, "fundamentally interpersonal." Furthermore, supervisors are also team members in this setting. Reliability Analyses (Table 5)

The reliability coefficients (alpha) obtained for Teamwork Expectations (.95), Social Cohesion Expectations (.91), Interpersonal Orientation (.88), and Importance of Interpersonal Reasons in Bid/Assignment Decisions (.94) (all utilized in Hypothesis 1) were very good. Alpha for Conflict Tolerance (.71) was acceptable, but somewhat lower than the others. As mentioned before, the Conflict 
Tolerance scale could benefit from further research and refinement. Use of the scale in other types of organizations is warranted to further test its reliability. It is also possible that modification of items could result in the reduction of underlying factors.

Alpha for Current Bid/Assignment Satisfaction Interpersonal Factors (.96) and Overall current Bid/Assignment Satisfaction (.91) were also very good. Alpha for Job Satisfaction (.77) was lower than expected for a sub-scale of a well-established instrument: the Job Diagnostic Survey (Hackman \& Oldham, 1975). Correlation Matrix (Table 6)

Only four relationships were not significant. Conflict Tolerance did not correlate with either Teamwork Expectations or Social Cohesion Expectations, nor with Current Bid Satisfaction. Also, Satisfaction with Current Bid Interpersonal Eactors did not correlate with Interpersonal orientation.

Some of the significant correlations that were found, i.e., Current Satisfaction - Interpersonal Factors and Overall current Satisfaction correlating with most other scales, may be a cause for concern. This finding might suggest that participants responded in ways analogous to the "Ieniency" or strictness errors committed by performance evaluation raters. (Anastasi \& Urbina, 1997). In other 
words, participants may have responded to most items based on a general affective response (Bagozzi \& Yi, 1990;

Mitchell, 1985). Although they are significant, none of these correlations exceed .37 .

Hypothesis 1 (Tables 7 and 8 )

Hypothesis 1 was supported (Table 7). Those with higher expectations (teamwork/social cohesion), higher in interpersonal orientation, and lower in conflict tolerance placed greater amounts of importance on interpersonal reasons (teamwork/social cohesion) in past bid/assignment decisions. This finding lends further support to the role of individual differences in voluntary turnover decisions (Judge, 1993).

It was noteworthy that all three variables contributed additional variance to the equation. Statistical regression often "hides" independent variables which are related to the dependent variable, because they are not significantly useful at later steps (they do not contribute substantial additional variance). Nevertheless, statistical regression is very useful when the sole goal of the equation is prediction, and is actually "considered the surest path to the best prediction equation." (Tabachnick \& Fidell, 1989, p. 147)

Unexpected, however, was the finding displayed in Table 8 (prediction of importance of "other reasons" for past 
bid/assignment decisions by two of the same variables: interpersonal orientation and conflict tolerance). One potential explanation for the success (to a lesser extent) of this second equation is that those who scored higher on interpersonal orientation and lower on conflict tolerance were simply more "sensitive" individuals. They may have felt that all factors were important in making significant decisions such as teammates and assignments.

As mentioned in the Results section, the magnitude of the relationship was much higher when predicting importance of interpersonal reasons (Mult. $\underline{R}=.57$ ), than when predicting "other reasons" (Mult. $\underline{R}=.27$ ). Furthermore, the proportion of variance accounted for in the equation predicting interpersonal reasons was more than four times higher than that accounted for in the "other reasons" equation (Adj. $\underline{R}$ Squared $=.31$ versus Adj. $\underline{R}$ squared $=.07$ ). Hypothesis 2a (Table 9)

Hypothesis 2 a was supported. Those changing bids/assignments were lower in current satisfaction than those staying in their assignment. This finding supports the idea of Intra-Organizational Turnover (including keeping the same job) as a real form of turnover (which is wellestablished as being negatively correlated with job satisfaction (Mobley et al., 1979). 
Eurther support is given to this hypothesis because General Job Satisfaction and Turnover were not related. Therefore, although General Job Satisfaction and Current Satisfaction were correlated, participants were truly reporting differential satisfaction levels between their job in general and their current bid/assignment.

Discriminant Analysis: Prediction of Turnover by Current Bid/Assignment Satisfaction Individual Items (Table 10) (Addendum to Hypothesis 2a)

This analysis was conducted for curiosity purposes; to query which of the Current Bid/Assignment Satisfaction items best predicted turnover. In descending order, the four items included in the discriminant function were:

cooperation and help team members offer each other, geographical location of the station, pay incentives, and assignment in general. This does appear to be a good "mix" of seemingly important items. In fact, the teamwork item (satisfaction with cooperation and help) is the broadest in scope of the four teamwork satisfaction items.

Examination of the discriminant function coefficients indicates a potential problem with item 10 (satisfaction with pay incentives); it is the only predictor yielding a negative coefficient. This pattern suggests that the item may be a suppressor variable: a variable that correlates with other independent variables, and " 'suppresses' 
variance that is irrelevant to prediction of the dependent variable." A suppressor variable actually "enhances the importance of other [independent variables] through this "suppression" (Tabachnick \& Fidell, p. 161).

To explore this possibility, crosstabulations were generated between the four items and turnover. Indeed, Item 10 was not correlated with turnover, but was correlated with the other predictor variables. It is likely, therefore, that item 10 is a suppressor variable. It enhances turnover prediction by items 1, 11, and 16, by removing irrelevant variance due to satisfaction with pay incentives.

As would be expected (Burke, 1995), subsequent analysis found that satisfaction with geographical location was related to distance of home to work. Therefore, even in this population of workers who commute during non-peak hours (early morning), distance to work is an important issue. Distance from home to work was measured as "Very far" to "Very close," rather than in mileage, because perception of distance is an individual determination. Hypothesis 2b (Table 11)

Hypothesis $2 \mathrm{~b}$ was supported. Those with higher individual turnover frequency were more likely to be changing bids/assignments. Because individual personality differences, such as that reflected in the preference to change assignments, may affect workplace motivations 
(Amabile, Hill, Hennessey, \& Tighe, 1994) and attitudes (Kirkcaldy, Furnham, \& Lynn, 1992), several possible explanations could explain this finding: 1) The high scorers may like a regular "change of pace." 2) The high scorers are difficult to get along with, so they continue searching for a comfortable assignment. 3) The high scorers are friendly, and like changing assignments to meet new people. 4) The high scorers are "picky," and, therefore, never happy with an assignment. 5) The high scorers are ambitious, and are trying to get as much experience as possible in different settings, on different apparatus, etc. 6) The high scorers are poor performers, and are subtly forced out of positions. Whatever the reason, this was an interesting finding.

Although most organizations do not have much intraorganizational turnover, the findings described above are generalizable to other settings. It may be saying that there are individuals who are more likely to change jobs/assignments if they could. It is certainly likely that individuals in more traditional work teams might enjoy the opportunity to change membership if possible. For these participants, this was an easy, available decision; usually it is not.

\section{Exploratory Analyses}

Some of the demographic findings were interesting, such as the fact that younger and less tenured workers scored 
higher on importance of interpersonal reasons in past bid/assignment decisions. It is possible that this is an issue of "generation gap." Younger people may be more inclined to grant importance to these issues, having been raised in more "touchy-feely" times. Alternatively, older workers may have become "jaded" over the years, and have less expectations (Snyder \& Mayo, 1991) and concerns about interpersonal issues (which are often so difficult).

Results showing firefighters to be higher than lieutenants in this variable is also interesting. Firefighters do have more choice in assignments, because there are simply many more firefighter positions. It may, therefore, be a reflection of the fact that they are better able to use interpersonal reasons if desired, while lieutenants have less ability to do so. Limitations

The main limitation to Hypothesis 1 is the fact that all variables were attitudinal. There was no "hard data" to corroborate, for example, importance of reasons in past bid/assignment decisions; it was strictly individuals' perceptions of their behavior (Crampton \& Wagner, 1994). Similarly, individual turnover frequency is also "according to the employee." Although it was also "self-reported, the turnover decision can be considered "hard data." At the point the questionnaires were completed, the employees had 
already made their final decision (which could not be reversed).

A second, similar problem is that employees were reporting past behavior in regard to reasons for past bid/assignment decisions and individual turnover frequency. This problem is one of accuracy: can we trust employees to reliably report past activity (Golden, 1992), especially when we are doubtful about their ability to report current phenomena (Mitchell, 1985)?

Although exact numbers were not available, it seemed that there was a higher response from those who were changing teams (in the 40 percent range), compared to those who remained with their team (in the 30 percent range). This impacts the generalizability of the results, because somewhat disproportionate weight was given to those who changed teams. Statistical analyses, and subsequent inferences, assume relatively equal response rates from all groups.

Theoretical Support for Investment Model

Although many theories and bodies of research were discussed in the literature review, Rusbult, et al.'s (1982; 1983; 1985; 1988) Investment Model (Commitment $=$ Satisfaction + Investment - Alternatives) provides the best foundation for the present study. The model was originally based upon the dynamics of relationships between partners, 
but has also been used in workplace settings. Due to living arrangements and high task interdependence, relationships among firefighters/emergency personnel can, in fact, be rather close. Good teamwork and group cohesion certainly enhance these relationships and, in turn, job satisfaction. The success of Hypothesis 2 a provides support for the model, which includes past satisfaction as a reason to stay in a relationship. The more satisfied participants in the study were, in fact, more likely to stay with their team. It is important to remember that the satisfaction assessed was not overall job satisfaction, but rather satisfaction with their current position (a good portion of which dealt with relationship (teamwork/social cohesion) issues). In fact, overall job satisfaction was not related to the turnover decision.

The rest of the model can also be applied to Hypothesis 2. Investment in the team relationship itself was, probably, rather low for most participants (though this would vary by individual) because teams change rather often. Alternatives, on the other hand, were great for most individuals because there were a lot of choices available (with exact number of choices dependent upon seniority). Therefore, satisfaction would be the most salient issue. Hypothesis 1's regression model also provides support for the Investment Model, albeit in a different way. The 
dependent variable was importance of interpersonal reasons in bid/assignment decisions, not turnover itself. However, because the predictor variables can all be explained by the Investment Model, their success gives the theory further support. Expectations is clearly explained by alternatives in the model. If the participants expected their alternatives to be better than their current experience, they would be more likely to leave. The question asked, however, was as follows: was this information utilized in the expected direction by those most likely to use it? In other words, were those who expected better alternatives more likely to use interpersonal reasons in their turnover decisions? The answer was yes.

The predictive value of interpersonal orientation and conflict tolerance can be explained similarly. Those who cared more about belonging and those who were less able to tolerate conflict, were more likely to use interpersonal reasons in their turnover decisions. Both interpersonal orientation and conflict tolerance can be understood as part of the model's investment component. Those with higher interpersonal orientation and lower conflict tolerance would be capable of investing more in their team relationships. If there was a positive investment, logic would explain that these individuals' greater usage of the interpersonal 
factors (teamwork/social cohesion) would further strengthen their desire to stay.

Therefore, the present study illustrates and supports the Investment Model in additional type of workplace. The model's versatility is also greatly supported in the study. It succeeds in explaining a different type of turnover (intra-organizational), and in asking two different questions (policy-capturing in regard to turnover decisions, in addition to simple turnover). Organizational Implications

The success of Hypothesis 1 (prediction of importance of interpersonal reasons in past bid/assignment decisions) has implications for work organizations in general. This finding supports past research (e.g., Organ, 1994; Sanchez \& Fraser, 1993) which has found that there are people who are more oriented toward interpersonal and altruistic attitudes and behavior. This fact affects (positively and/or negatively) the many organizational functions that have an interpersonal component. For example, such persons might be wonderful on the telephone with customers, or they might spend too much time on the telephone, annoying customers. Similarly, they may be motivated by occasional social events at work, they may enjoy helping others and training new employees and they may be terrific in team-building exercises, However, they may also require a very cooperative 
environment and regular praise, and eschew too much independent work.

Because most employees cannot leave organizations as easily as the participants in the study, smart organizations should understand employees' needs whenever possible. Although no paper-and-pencil measures of interpersonal orientation or behavior may be given, attitudes are often somewhat transparent (through observed behavior). It may be possible to help employees with specific personalities, such as high interpersonal orientation, find suitable positions within an organization. In fact, the study of intraorganizational turnover lends itself to the idea that, perhaps, there should be more support for transfer within organizations (if fiscally and logistically feasible). Perhaps such transfers, in conjunction with career development, could enhance employee morale and satisfaction, and decrease "pigeon-holing" employees into positions.

Similarly, Hypothesis $2 b^{\prime}$ s findings shows that there are individuals that are more inclined, beyond situationspecific unhappiness, toward turnover behavior. In most organizations, however, they are unable to carry out this desire. If organizational leaders understood this, they could offer these individuals (and others) more job rotation, different assignments on occasion (job enrichment), and encourage their attendance at training and 
development classes. Such strategies may help to keep these employees motivated (Aldag \& Brief, 1979 as cited in Miner, 1992) and satisfied (in lieu of turnover). Finally, there is a related possibility that individuals prone to turnover would not be happy for any length of time, even if turnover was an easy option.

The success of the Investment Model in explaining the study's findings also has organizational implications. Organizations should better understand that some work relationships can be analogous to regular partner/family relationships. In such settings, as in the present one, concerted effort should be made to enhance these relationships. It is not enough to simply sponsor an occasional team-building (or other cooperative training) session. Careful analysis must be made of the work environment's unique characteristics, and training/support should be tailored to the setting.

As stated earlier, most employees do not have the luxury of changing assignments every six months as do these employees. This fact further necessitates fostering of the best possible relationships among close-working units. This is important, however, even in the present setting. Better relationships could lead to less turnover, more stability, and more satisfied employees. Changing teams could then be 
done most often for a "change of pace," rather than to leave a bad team relationship.

General Contributions

To review, the contributions of this study to the literature are listed below. These are followed by a more detailed explanation of the contribution to the turnover literature.

1) Creation of a Conflict Tolerance scale for work settings.

2) Provision of additional theoretical support of the Investment Model.

3) Use of previous experience (in place of a "realistic job preview") (Wanous et al., 1992) as a determinant of later expectations.

4) Addition to small amount of research regarding seifselected teams/groups.

5) Addition to small amount of research regarding intensely social work settings.

6) Addition to small amount of research regarding satisfaction with teamwork.

\section{Turnover}

There are three important features (contributions) found in the test of Hypothesis 1 (predicting importance of interpersonal reasons jn past bid/assignment decisions): 
1) Investigation of complete "Intra-Organizational Turnover" (same organization, same job, different team/location), and a model regarding related interpersonal factors.

2) Use of "hard" criterion for turnover, rather than "intent to quit." Although intent to turnover and actual turnover are related, they are distinct variables (Tett \& Meyer, 1993). Actual turnover is the more meaningful of the two measures, and reflects actual behavior (rather than thought processes).

3) Examination of individual differences in team turnover decisions, through the control of all other variables.

The third contribution is perhaps the most significant. By controlling other factors inherent in turnover decisions (e.g., loss of employment, income, tenure, and benefits; loss of actual job function; change of work schedule; possible geographical move), it was possible to focus on individual differences (importance of interpersonal reasons in team turnover decisions). This study of individual factors provides a unique examination of voluntary turnover. There are few, if any, other organizations in which such a controlled investigation is possible. For example, police officers change assignments, but their work schedule may change, and there is no team choice. Airline employees 
change teams, but work schedules also change. In the present study, turnover creates only two changes: station location and team members; the other components of the job remain the same.

The contribution of Hypothesis $2 \mathrm{~b}$ is also unique: the study of past turnover frequency in relation to current turnover decisions. Finally, the investigations of all three hypotheses contribute by combining the topics of selfselected groups and turnover.

Future Research

There is much additional research that could be conducted as extension of, or tangential to, this study. As already suggested, the Conflict Tolerance scale could benefit from further study and usage. Conflict is inherent in all organizations, and individual difference in tolerance affects more workplace function than is likely realized. For example, those who are less tolerant may avoid senseless arguments, but may also avoid making helpful suggestions that could be challenged. As mentioned, a conflict tolerance scale could be used in organizational development and individual career planning.

More intra-organizational turnover research is also suggested. Although the self-selection in this study is unique, there are other occupations for which lateral movement is possible: e.g., nurses, police officers, 
teachers, secretaries. It would also be interesting to focus on the difference in turnover decisions and experience in intra-organizational turnover versus those changing organizations, but not jobs; e.g., nurses who change "floors" versus nurses who change hospitals.

If further research could be conducted in this fire rescue department, it would be insightful to examine the impact of total self-selection on the functioning and makeup of teams. For example, do the teams become increasingly homogeneous as might be predicted by Schneider's (1987) attraction-selection-attrition model?

Rusbult and Farrell's (1983) discussion of the "process of change" that occurs prior to leaving could also be further examined in this setting. The thought processes of the participants could be evaluated throughout the "bid cycle," leading to the final semi-annual turnover decision. One important related question would be the effect of these turnover thought processes on teamwork performance. 
LIST OF REFERENCES 
Amabile, T. M., Hill, K. G., Hennessey, B. A., \& Tighe, E. M. (1994). The Work Preference Inventory: Assessing intrinsic and extrinsic motivational orientations. Journal of Personality and Social Psychology, 66 (5), 950-967.

Amason, A. C. (1996). Distinguishing the effects of functional and dysfunctional conflict on strategic decision making: Resolving a paradox for top management teams. Academy of Management Journal, 39 (1), 123-148.

Amason, A. C., Thompson, K. R., Hochwarter, W. A., \& Harrison, A. W. (1995). Conflict: An important dimension in successful management teams. Organizational Dynamics, 24 (2), 20-35.

Anastasi, A., Urbina, S. (1997). Psychological testing. Upper Saddle River, NJ: Prentice-Hall, Inc.

Anastasio, P., Bachman, B., Gaertner, S., \& Dovidio, J. (1997). In R. Spears, P. J. Oakes, N. Ellemers, \& S. A. Haslam (Eds.), The social psychology of stereotyping and group life, (pp. 236-256). Cambridge: Blackwell Publishers, Inc.

Arnold, H. J., \& Feldman, D. C. (1982). A multivariate analysis of the determinants of job turnover. Journal of Applied Psychology, 67 (3), 350-360.

Bagozzi, R. P., \& Yi, Y. (1990). Assessing method variance in multitrait-multimethod matrices: The case of self-reported affect and perceptions at work. Journal of Applied Psychology, 75 (5), 547-560.

Bass, B. M., \& Dunteman, G. (1963). Behavior in groups as a function of self-interaction, and task orientation. Journal of Abnormal and Social Psychology, 66 (5), 419-428.

Bornewasser, M., \& Bober, J. (1987). Individual, social group and intergroup behavior. Some conceptual remarks on the social identity theory. European Journal of Social Psychology, 17, 267-276.

Brawley, L. R., Carron, A. V., \& Widmeyer, W. N. (1993). The influence of the group and its cohesiveness on perceptions of group goal-related variables. Journal of Sport and Exercise Psychology, 15, 245-260. 
Brayfield, A. H., \& Crockett, W. H. (1955). Employee attitudes and employee performance. Psychological Bulletin, 5, 396-422.

Burke, R. J. (1995). Commuting to work. Perceptual and Motor Skills, 80 (1), 49-50.

Campion, M. A. (1991). Meaning and measurement of turnover: Comparisons of alternative measures and recommendations for research. Journal of Applied Psychology, 76 (2), 199-212.

Carron, A. V., Widmeyer, W. N., \& Brawley, L. R. (1985). The development of an instrument to assess cohesion in sport teams: The Group Environment Questionnaire. Journal of Sport Psychology, 7, 244-266.

Carron, A. V., Widmeyer, W. N., \& Brawley, L. R. (1988). Group cohesion and individual adherence to physical activity. Journal of Sport and Exercise Physiology, 10, 127138 .

Carsten, J. M., \& Spector, P. E. (1987). Unemployment, job satisfaction, and employee turnover: A meta-analytic test of the Muchinsky model. Journal of Applied Psychology, 72 (3), 374-381.

Cartwright, D. (1968). The nature of group cohesiveness. In D. Cartwright \& A. Zander (Eds.), Group dynamics: Research and theory (pp. 91-109). New York: Harper \& Row.

Chao, G. T., O'Leary-Kelly, A. M., Wolf, S., Klein, H. J., \& Gardner, P. D. (1994). Organizational socialization: Its content and consequences. Journal of Applied Psychology, 79 (5), 730-743.

Chick, G. E., Roberts, J. M., \& Romney, A. K. (1991). Conflict and quitting in the Monday nite pool league. Leisure Sciences, 13, 295-308.

Cohen, J. (1992). A power primer. Psychological Bulletin, 112 (1), 155-159.

Coovert, M. D., Craiger, J. P., \& Cannon-Bowers, J. A. (1992). Innovations in modeling and simulating team performance: Implications for decision making. In Team effectiveness and decision making in organizations (pp.149203). San Francisco, CA: Jossey-Bass. 
Cortina, J. M. (1993). What is coefficient alpha?: An examination of theory and application. Journal of Applied Psychology, 78 (1), 98-104.

Cotton, J. I., \& Tuttle, J. M. (1986). Employee turnover: A meta-analysis and review with implications for research. Academy of Management Review, 11 (1), 55-70.

Crampton, S. M., \& Wagner III, J. A. (1994). Perceptpercept inflation in microorganizational research: An investigation of prevalence and effect. Journal of Applied Psychology, 79 (1), 67-76.

Dipboye, R. L., Smith, C. S., \& Howell, W. C. (1994). Understanding industrial and organizational psychology: An integrated approach. Fort Worth, TX: Harcourt Brace College

Eisenstein, A. (1991). The developmental line of conflict tolerance. Contemporary Psychotherapy Review, 6, $80-93$.

Farrell, D., \& Rusbult, C. E. (1981). Exchange variables as predictors of job satisfaction, job commitment, and turnover: The impact of rewards, costs, alternatives, and investments. Organizational Behavior and Human Performance 28, 78-95.

Farrell, D., \& Rusbult, C. E. (1992). Exploring the exit, voice, loyalty, and neglect typology: The influence of job satisfaction, quality of alternatives, and investment size. Employee Responsibilities and Rights Journal, 5 (3), 201-218.

Fisher, S. G., Macrosson, W. D. K., \& Walker, C. A. (1995). EIRO-B: The power of love and the love of power. Psychological Reports, 76, 195-206.

Gardenswartz, L., \& Rowe, A. (1994). Diverse teams at work: Capitalizing on the power of diversity. Chicago, IL: Irwin.

Gear, T. E., Marsh, N. R., \& Sergent, P. (1985). Semiautomated feedback and team behavior. Human Relations, 38 (8), 707-721. 
George, J. M., \& Bettenhausen, K. (1990). Understanding prosocial behavior, sales performance, and turnover: A group-level analysis in a service context. Journal of Applied Psychology, 75 (6), 698-709.

Golden, B. R. (1992). The past is the past - or is it? The use of retrospective accounts as indicators of past strategy. Academy of Management Journal, 35 (4), 848-860.

Goodman, P. S., Ravlin, E. C., \& Argote, L. (1986). Current thinking about groups: Setting the stage for new ideas. In Designing effective work groups, (pp.1-33). San Fransisco: Jossey-Bass Publishers.

Graen, G., Cashman, J. F., Ginsburgh, S., \& Schiemann, W. (1977). Effects of linking-pin quality upon the quality of working life of lower participants: A longitudinal investigation of the managerial understructure. Administrative Science Quarterly, 22, 491-504.

Graen, G., \& Ginsburgh, S. (1977). Job resignation as a function of role orientation and leader acceptance: A longitudinal investigation of organizational assimilation. Organizational Behavior and Human Performance, 19, 1-17.

Hackman, J. R. (1990). Work teams in organizations: An orienting framework. In J. R Hackman (Ed.), Groups that work (and those that don't): Creating conditions for effective teamwork, (pp. 1-14). San Fransisco: Jossey-Bass Publishers.

Hackman, J. R., \& Oldham, G. R. (1975). Development of the job diagnostic survey. Journal of Applied Psychology, 60, 159-170.

Hand, H. H., Estafen, B. D., \& Sims, Jr., H. P. (1975). How effective is data survey and feedback as a technique of organization development? An experiment. Journal of Applied Behavioral Science, 11 (3), 333-347.

Hellman, C. M. (1994). Participation in decision making and committee members' intent to remain. Psychological Reports, 74, 490 .

Hirschman, A. O. (1970). Exit, voice and loyalty: Responses to decline in firms, organizations and states. Cambridge: Harvard University Press. 
Hom, P. W., Caranikas-Walker, F., Prussia, G. E., \& Griffeth, R. W. (1992). A meta-analytical structural equations analysis of a model of employee turnover. Journal of Applied Psychology, 77 (6), 890-909.

Irving, P. G., \& Meyer, J. P. (1994). Reexamination of the met-expectations hypothesis: A longitudinal analysis. Journal of Applied Psychology, 79 (6), 937-949.

Iverson, R. D., \& Roy, P. (1994). A causal model of behavioral commitment: Evidence from a study of Australian blue-collar employees. Journal of Management, 20 (1), 15-41.

Jackson, S. E., Brett, J. F., Sessa, V. I., Cooper, D. M., Julin, J. A., \& Peyronnin, K. (1991). Some differences make a difference: Individual dissimilarity and group heterogeneity as correlates of recruitment, promotion, and turnover. Journal of Applied Psychology, 76 (5), 675-689.

Jehn, K. A. (1995). A multimethod examination of the benefits and detriments of intragroup conflict. Administrative Science Quarterly, 40, 256-282.

Jin, P. (1993). Work motivation and productivity in voluntarily formed work teams: A field study in China. Organizational Behavior and Human Decision Processes, 54, 133-155.

Johnson, J., \& Arneson, P. (1991). Women expressing anger to women in the workplace: Perceptions of conflict resolution styles. Women's Studies in Communications, 14 (2), 24-41.

Judge, T. A. (1993). Does affective disposition moderate the relationship between job satisfaction and voluntary turnover? Journal of Applied Psychology, 78 (3), 395-401.

Katz, D. \& Kahn, R. L. (1978). The social psychology of organizations. New York: John Wiley \& Sons.

Kelley, H. H., \& Thibaut, J.W. (1978). Interpersonal relations: A theory of interdependence. New York: John Wiley \& Sons.

Kirkcaldy, B. D., Eurnham, A., \& Lynn, R. (1992). Individual differences in work attitudes. Personality and Individual Differences, 13 (1), 49-55. 
Klimoski, R., \& Jones, R. G. (1995). Staffing for effective group decision making: Key issues in matching people and teams. In Team effectiveness and decision making in organizations (pp. 291-332). San Francisco, CA: Jossey-

Kubes, M. (1992). Cognitive style and interpersonal behaviour: The Kirton Adaption-Innovation and Schutz's FIRO(2), 33-38. Psychology: A Journal of Human Behavior, 29

Latane', B., Williams, K., \& Harkins, S. (1979). Many hands make light the work: The causes and consequences of social loafing. Journal of Personality and Social Psychology, 37, 823-832.

Lee, T. W., \& Mitchell, T. R. (1994). An alternative approach: The unfolding model of voluntary employee turnover. Academy of Management Journal, 19 (1), 51-89.

Lee, T. W., Mitchell, T. R., Wise, L., Fireman, S. (1996). An unfolding model of voluntary employee turnover. Academy of Management Journal, 39 (1), 5-36.

Major, D. A., Kozlowski, S. W. J., Chao, G. T., \& Gardner, P. D. (1995). A longitudinal investigation of newcomer expectations, early socialization outcomes, and the moderating effects of role development factors. Journal of Applied Psychology, 80 (3), 418-431.

Manning, F. J., \& Fullerton, T. D. (1988). Health and well-being in highly cohesive units of the U.S. Army. Journal of Applied Social Psychology, 18 (6), 503-519.

Marriott, A., Sexton, L., \& Staley, D. (1994). Components of job satisfaction in psychiatric social workers. Health and Social Work, 19 (3), 199-205.

Michaels, C. E., \& Spector, P. E. (1982). Causes of employee turnover: A test of the Mobley, Griffeth, Hand, and Meglino Model. Journal of Applied Psychology, 67 (1), 53-59.

Miller, H. E., Katerberg, R., \& Hulin, C. L. (1979). Evaluation of the Mobley, Horner, and Hollingsworth model of employee turnover. Journal of Applied Psychology, 64, 509517.

Miner, J. (1992). Industrial-organizational psychology. New York: McGraw-Hill, Inc. 
Mitchell, T. R. (1985). An evaluation of the validity of correlational research conducted in organizations. Academy of Management Journal, 10 (2), 192-205.

Mobley, W. H. (1977). Intermediate linkages in the relationship between job satisfaction and employee turnover. Journal of Applied Psychology, 62 (2), 237-240.

Mobley, W. H., Griffeth, R. W., Hand, H. H., \& Meglino, B. M. (1979). Review and conceptual analysis of the employee turnover process. Journal of Applied Psychology, 86 (3), 493-522.

Mobley, W. H., Horner, S. O., \& Hollingsworth, A. T. (1978). An evaluation of precursors of hospital employee turnover. Journal of Applied Psychology, 63 (4), 408-414.

Muchinsky, P. M., \& Tuttle, M. L. (1979). Employee turnover: An empirical and methodological assessment. Journal of Vocational Behavior, 14, 43-77.

Muchinsky, P. M., \& Morrow, P. C. (1980). A multidisciplinary model of voluntary employee turnover. Journal of Vocational Behavior, 17, 263-290.

Neuman, G. A., Edwards, J. E., Raju, N. S. (1989). Organizational development interventions: A meta-analysis of their effects on satisfaction and other attitudes. Personnel Psychology, 42, 461-483.

O'Reilly, C. A., Caldwell, D. F., \& Barnett, W. P. (1989). Work demography, social integration, and turnover. Administrative Science Quarterly, 34, 21-37.

Organ, D. W. (1994). Personality and organizational citizenship behavior. Journal of Management, 20 (2), 465478 .

Pearson, C. A. L. (1995). The turnover process in organizations: An exploration of the role of met-unmet expectations. Human Relations, 48 (4), 405-418.

Porter, L. W. \& Steers, R. M. (1973). Organizational, work, and personal factors in employee turnover and absenteeism. Psychological Bulletin, 80, 151-176. 
Posner, B. Z., \& Randolph, W. A. (1979). Perceived situational moderators of the relationship between role ambiguity, job satisfaction, and effectiveness. Journal of Social Psychology, 109, 237-244.

Premack, S. L., \& Wanous, J. P. (1985). A meta analysis of realistic job preview experiments. Journal of Applied
Psychology, 70, 706-719.

Price, J. L., \& Mueller, C. W. (1986). Absenteeism and turnover of hospital employees. Greenwich, CT: JAI Press.

Rahim, M. A. (1983). A measure of styles of handling interpersonal conflict. Academy of Management Journal, 26
(2), 368-376.

Riordan, C. M., \& Shore, L. M. (1997). Demographic diversity and employee attitudes: An empirical examination of relational demography within work units. Journal of Applied Psychology, 82 (3), 342-358.

Rusbult, C. E. (1983). A longitudinal test of the investment model: The development (and deterioration) of satisfaction and commitment in heterosexual involvements. Journal of Personality and Social Psychology 45 (1), 101117.

Rusbult, C. E., \& Farrell, D. (1983). A longitudinal of the investment model: The impact on job satisfaction, job commitment, and turnover of variations in rewards, costs, alternatives, and investments. Journal of Applied Psychology, 68 (3), 429-438.

Rusbult, C. E., Farrell, D., Rogers, G., \& Mainous III, A. G. (1988). Impact of exchange variables on exit, voice, loyalty, and neglect: An integrative model of responses to declining job satisfaction. Academy of Management Journal, 31 (3), 599-627.

Rusbult, C., \& Lowery, D. (1985). When bureaucrats get the blues: Responses to dissatisfaction among federal employees. Journal of Applied Social Psychology, 15 (1), 80103.

Rusbult, C. E., Zembrodt, I. M., \& Gunn, L. K. (1982). Exit, voice, loyalty, and neglect: Responses to dissatisfaction in romantic involvements. Journal of Personality and Social Psychology, 43 (6), 1230-1242. 
Saavedra, R., Earley, P. C., \& Van Dyne, L. (1993). Complex interdependence in task-performing groups. Journal of Applied Psychology, 78 (1), 61-72.

Salas, E., Dickinson, T. L., Converse, S. A., \& Tannenbaum, S. I. (1992). In Teams: Their training and performance (pp. 3-29). Norwood, N.J.: Ablex Publishing Corporation.

Sanchez, J. I., \& Fraser, S. L. (1993). Development and validation of the Corporate Social style Inventory: $\mathrm{A}$ measure of customer service skills (Report No. 93-108). Cambridge, MA: Marketing Science Institute.

Schneider, B. (1987). The people make the place. Personnel Psychology, 40, 437-453.

Schutz, W. C. (1958). EIRO: A three-dimensional theory of interpersonal behavior. New York: Reinhart.

Seashore, S. E. (1954). Group cohesiveness in the industrial work group. Ann Arbor, MI: Institute for Social Research-University of Michigan.

Seers, A. (1989). Team-member exchange quality: A new construct for role-making research. Organizational Behavior and Human Decision Processes, 43, 118-135.

Sessa, V. I. (1996). Using perspective taking to manage conflict and affect in teams. Journal of Applied Behavioral Science, 32 (1), 101-115.

Sheridan, J. E. (1985). A catastrophe model of employee withdrawal leading to low job performance, high absenteeism, and job turnover during the first year of employment. Academy of Management Journal, 28 (1), 88-109.

Snyder, R. A., \& Mayo, E. (1991). Single versus multiple causes of the age/job satisfaction relationship. Psychological Reports, 68 (3), 1255-1262.

Stagner, R. (1962). Personality variables in unionmanagement relations. Journal of Applied Psychology, 46 (5), 350-357. 
Steers, R. M., \& Mowday, R. T. (1981). Employee turnover and post-decision accommodation processes. In L. L. Cummings \& B. M. Staw (Eds.) Research in

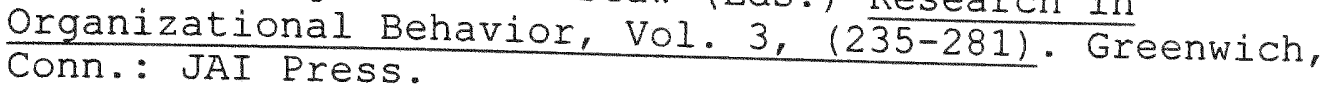

Steel, R. P. \& Ovalle, N. K. II. (1984). A review and meta-analysis of research on the relationship between behavioral intentions and employee turnover. Journal of Applied Psychology, 69, 673-686.

Summers, I., Coffelt, T., \& Horton, R. E. (1988). Work-group cohesion. Psychological Reports, 63, 627-636.

Sundstrom, E., De Meuse, K. P., \& Futrel1, D. (1990). Work teams: Applications and effectiveness. American Psychologist, 45 (2), 120-133.

Tabachnick, B. G., \& Fidell, L. S. (1989). Using multivariate statistics. New York: HarperCollins Publishers, Inc.

Tajfel, H. (1981). Human groups and social categories: Studies in social psychology. Cambridge: Cambridge University Press.

Tajfel, H. (1982). Social psychology of intergroup relations. Annual Review of Psychology, 33, 1-39.

Tajfel, H., \& Turner, J. C. (1986). The social identity theory of intergroup behavior. In $S$. Worchel and $W$. G. Austin (Eds.), The psychology of intergroup relations (pp. 7-24). Chicago: Nelson-Hall.

Tett, R. P., \& Meyer, J. P. (1993). Job satisfaction, organizational commitment, turnover intention, and turnover: Path analyses based on meta-analytic findings. Personnel Psychology, 46, 259-293.

Thibaut, J. W., \& Kelley, H. H. (1959). The social psychology of groups. New York: John Wiley \& Sons, Inc.

Tsui, A. S., \& Egan, T. D. (1992). Being different: Relational demography and organizational attachment. Administrative Science Quarterly, 37, 549-579. 
Tsui, A. S., \& O'Reilly III, C. A. (1989). Beyond simple demographic effects: The importance of relational demography in superior-subordinate dyads. Academy of Management Journal, 32 (2), 402-423.

Turner, J. C., \& Giles, H. (1981). In J. C. Turner \& H. Giles (Eds.), Intergroup behaviour (pp.1-32). Chicago:

Tziner, A., \& Vardi, Y. (1982). Effects of command style and group cohesiveness on the performance effectiveness of self-selected tank crews. Journal of Applied Psychology, 67 (6), 769-775.

Van Zelst, R. H. (1951). Worker popularity and job satisfaction. Personnel Psychology, 4, 405-412.

Van Zelst, R. H. (1952). Validation of a sociometric regrouping. Journal of Abnormal and Social Psychology 47,
299-301.

Von der Lippe, A. L. (1986). Ego development in women without higher education. Scandinavian Journal of Psychology, 27 (2), 150-162.

Wageman, R. (1995). Interdependence and group effectiveness. Administrative Science Quarterly 40, 145-180.

Walling, M. D., Duda, J. L., \& Chi, L. (1993). The Perceived Motivational Climate in Sport Questionnaire: Construct and predictive validity. Journal of Sport and Exercise Psychology, 15, 172-183.

Wanous, J. P., Poland, T. D., Premack, S. L., \& Davis, K. S. (1992). The effects of met expectations on newcomer attitudes and behaviors: A review and meta-analysis. Journal of Applied Psychology, 77 (3), 288-297.

Webber, R. A. (1974). Majority and minority perceptions and behavior in cross-cultural teams. Human Relations, 27 (9), 873-889.

Wiersema, M. F., \& Bird, A. (1993). Organizational demography in Japanese firms: Group heterogeneity, individual dissimilarity, and top management turnover. Academy of Management Journal, 36 (5), 996-1025. 
Williams, J. M., \& Hacker, C. M. (1982). Casual relationships among cohesion, satisfaction, and performance in women's intercollegiate field hockey team. Journal of Sport Psychology, 4, 324-337.

Youngblood, S. A., Mobley, W. H., \& Meglino, B. M. (1983). A longitudinal analysis of the turnover process. Journal of Applied Psychology, 68 (3), 507-516. 


\section{APPENDIX A}

CONELICT TOLERANCE QUESTIONNAIRE 28 PILOT-TESTED ITEMS 
A

Disagree

Strongly

$\begin{array}{cc}\text { B } & C \\ \text { Disagree } & \text { Neither } \\ & \text { Agree } \\ & \text { nor } \\ & \text { Disagree }\end{array}$

D

Agree

E

Agree

Strongly

1) Conflict is to be expected among a group of people who work closely together.

2) I would rather work with good workers who disagree a lot, than poor workers who always get along.

3) Conflict is healthy for an organization, because it shows where change is needed.

4) Conflict is healthy for an organization, because it can resolve problems and "make things better".

5) When there is workplace conflict, I find it difficult to get my job done.

6) When there is workplace conflict, I find it difficult to go to work.

7) When people disagree at work, I try to "smooth things over".

8) When there is conflict at work, I think about it at home.

9) When there is conflict at work, it bothers me at home.

10) I am bothered by friction between myself and my co-workers.

11) I am bothered by friction among others at work.

12) Conflict can make work more exciting.

13) People should not let criticism bother them, because it's often for their own good.

14) If a person cannot handle conflict in their job, the job may not be right for them.

(CONTINUED) 
Page $2 / 2$

TO WHAT EXTENT DO YOU AGREE WITH THE FOLLOWING?

\begin{tabular}{ccccc}
\hline A & B & C & D & E \\
Disagree & Disagree & Neither & Agree & Agree \\
Strongly & Agree & & Strongly \\
& nor & & \\
& & Disagree & & \\
& & & \\
\hline
\end{tabular}

15) I realize that certain people are difficult to work with, and I just "figure" that it is their problem.

16) I do not let work conflicts interefere with my non-work relationships with co-workers.

17) I try to stay out of work conflicts when possible.

18) Working through conflict makes a work group more cohesive.

19) Conflict can energize a work group.

20) I can't help feeling "strange" among those with whom I have work disagreements.

21) It is important to get along with members of your work group.

22) I go to work to get a job done; conflict is irrelevant.

23) I take sides in others' work disagreements.

24) If work conflict really bothers a person, they aren't strong enough.

25) When I sense a conflict starting at work, I try to prevent it from getting worse.

26) Usually a work conflict just needs time to "straighten itself out".

27) Training in work conflict management is not necessary; being able to solve conflict is part of human nature.

28) Maintaining harmony should be a goal of any work group.

29) A - If you have ever worked full-time.

B - If you have ever worked part-time (but not full-time).

C- If you have never worked. 
APPENDIX B

FOCAL STUDY QUESTIONNAIRE 
Dear Firefighter/Lieutenant/Captain working in Operations:

My name is Sharon Dolfi. I currently work in the department's Planning Section, and previously supervised the Personnel Bureau. Beginning below is a survey I'm using for my dissertation research regarding teamwork. I would greatly appreciate your help in filling out the survey. It should only take 10-15 minutes, and is anonymous. "If you hold a CR position, please consider your team/crew as the unit or units with which you most identify.*

Please read the instructions for each section of the survey. When you are finished, please put the survey back in the same envelope, seal it, and place it in the large sealed envelope provided for your station (ask the Station Capt. or Coordinator). I hope you find the survey interesting. If you have any questions or comments, please call me at 596-8502. Thank you very much for your help.

Sincerely,

\section{Sharon Dolfi}

Based upon your PAST EXPERIENCE within the department, to what extent do you agree with the following statements? "Team-members" refers to a crew, including Unit O.I.C. These items refer to interaction during FORMAL JOB TASKS.

$\begin{array}{lclcc}1 & 2 & 3 & 4 & 5 \\ \text { Disagree } & \text { Disagree } & \text { Neither Agree } & \text { Agree } & \text { Agree } \\ \text { Strongly } & & \text { nor Disagree } & & \text { Strongly }\end{array}$

I expect team-members to share accomplishments with each other.

I expect team-members to communicate well with each other.

I expect team-members to help each other with job tasks.

I expect team-members to recognize each others' potential.

I expect team-members to readily switch responsibilities with others when needed.

I expect team-members to teach, and learn from, each other.

I expect team-members to cooperate.

I expect team-members to be interested in improving teamwork.

I expect team-members to trust each other.

I expect team-members to appreciate each others' efforts.

I expect team-members to readily work toward reaching a consensus and/or compromise when needed.

I expect team-members to readily give and accept constructive criticism.

I expect team-members to easily accept extra responsibility when needed.

I expect team-members to value each others' ideas.

I expect team-members to help each other with job-related problems and needs.

(CONTINUED ON BACK OF THIS PAGE) 
Based upon your PAST EXPERIENCE within the department, to what extent do you agree with the following statements? "Co-workers" refers to everyone in a station.

$\begin{array}{ccccc}1 & 2 & 3 & 4 & 5 \\ \text { Disagree } & \text { Disagree } & \text { Neither Agree } & \text { Agree } & \text { Agree } \\ \text { Strongly } & & \text { nor Disagree } & & \text { Strongly }\end{array}$

I expect co-workers to be friendly towards each other.

I expect co-workers to take a personal interest in each other.

I expect co-workers to look forward to being together each shift.

I expect co-workers to defend each other from criticism.

I expect co-workers to "stick together".

I expect co-workers to enjoy planning/preparing/eating meals together.

I expect co-workers to enjoy non-work-activities together during their shift (talking, watching T.V., exercising, etc.) together

I expect co-workers to help each other with non-work-related problems/issues, if asked.

I expect co-workers to enjoy holidays together during their shift.

I expect co-workers to share news of family/friends with each other.

Each of the statements below is something that a person might say about his or her job. Please indicate your own, personal feelings about your job by marking how much you agree with each statement.

$\begin{array}{ccccc}1 & 2 & 3 & 4 & 5 \\ \text { Disagree } & \text { Disagree } & \text { Neither Agree } & \text { Agree } & \text { Agree } \\ \text { Strongly } & & \text { nor Disagree } & & \text { Strongly }\end{array}$

My opinion of myself goes up when I do this job well.

Generally speaking, I am very satisfied with this job.

I feel a great sense of personal satisfaction when I do this job well.

I do not think of quitting this job very often.

I feel bad and unhappy when I discover that I have performed poorly on this job.

I am generally satisfied with the kind of work I do in this job.

My own feelings generally are affected by how well I do this job.

For each statement below, decide which of the following answers best applies to you.

$\begin{array}{ccccc}1 & 2 & 3 & 4 & 5 \\ \text { Never or Rarely } & \text { Occasionally } & \text { Sometimes } & \text { Often } & \text { Usually }\end{array}$

I tend to join social organizations when I have an opportunity.

I try to include other people in my plans.

I try to have people around me.

When people are doing things together, I tend to join them.

I try to avoid being alone.

I like people to ask me to participate in their discussions.

I like people to invite me to things.

I like people to include me in their activities.

(CONTINUED ON NEXT PAGE) 
To what extent do you agree with the following?

$\begin{array}{ccccc}1 & 2 & 3 & 4 & 5 \\ \text { Disagree } & \text { Disagree } & \text { Neither Agree } & \text { Agree } & \text { Agree } \\ \text { Strongly } & & \text { nor Disagree } & & \text { Strongly }\end{array}$

When there is workplace conflict, I find it difficult to get my job done.

When there is workplace conflict, I find it difficult to go to work.

When there is conflict at work, it bothers me at home.

I am bothered by friction between myself and my co-workers.

I am bothered by friction among others at work.

Conflict can make work more exciting.

If a person cannot handle conflict in their job, the job may not be right for them.

I do not let work conflicts interfere with my non-work relationships with co-workers.

Conflict can energize a work group.

I can't help feeling strange among those with whom I have work disagreements.

If work conflict really bothers a person, they aren't strong enough.

Maintaining harmony should be a goal of any work group.

Consider ALL bid or assignment decisions YOU have made during your career. Rate the following factors in terms of importance to you when DECIDING whether to leave or stay with a team (unit), and/or when DECIDING which new team (unit) to bid/choose. (New employees: try to predict)

12

Unimportant
2

Not too

Important
3

Neutral or

Not Applicable
4

Important

Geographical locations of the stations

The stations themselves (physical aspects of the facilities)

The residents/visitors the stations served

The types of calls (alarms) the stations received

Wanting to change shifts

How busy/slow the stations were

Wanting to change assignment (ex., vehicle type, rescue/suppression; driver; specialized units)

Your supervisors (Unit O.I.C., Battalion Chief, Division Chief)

The hospitals with which you dealt

Pay incentives

Wanting a "fresh assignment," change of pace.

**("Co-workers" below refers to everyone in your assigned stations.)

Friendliness of co-workers

Amount of personal interest co-workers took in each other

Extent to which co-workers enjoyed being together socially during shift (enjoying meals, sharing news of family/friends, sharing holidays, watching TV, exercising, etc.)

How much co-workers "stuck together"

**("Team-members" below refers to your assigned crews, including Unit O.I.C.'s)

Satisfaction with cooperation and help team-members offered each other

Satisfaction with team-members' appreciation of each others' efforts and ideas

Satisfaction with communication among team-members

Satisfaction with compromise among team-members

(CONTINUED ON BACK OF THIS PAGE) 
How SATISFIED are you with the following factors in your CURRENT bid/assignment?

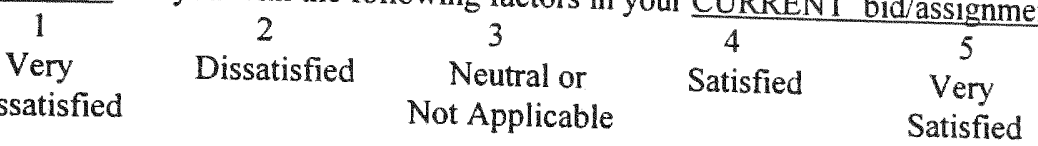

Geographical location of the station

The station itself (physical aspects of the facility)

The residents/visitors the station serves

The types of calls (alarms) the station receives

Your shift

The activity level of the station (how busy/slow the station is)

Assignment itself (vehicle type; rescue v. suppression, driver, specialized units)

Supervisors (Unit O.I.C., Battalion Chief, Division Chief)

The hospitals with which you deal

Pay incentives

Assignment in general

**("Co-workers" below refers to everyone in your assigned station.)

Friendliness of co-workers

Amount of personal interest co-workers take in each other

Extent to which co-workers enjoy being together socially during shift (enjoying meals, sharing

news of family/friends, sharing holidays, watching TV, exercising, etc.)

How much co-workers "stick together"

**("Team-members" below refers to your assigned crew, including Unit O.I.C.)

Satisfaction with cooperation and help team-members offer each other

Satisfaction with team-members' appreciation of each others' efforts and ideas

Satisfaction with communication among team-members

Satisfaction with compromise among team-members

Are you bidding out, or changing assignments, in the new bid period (beginning March 10)?

Yes

No

Approximately how often do you change teams/bids/assignments?

Every bid period, or almost every bid period ___ Every 1-2 years

Every 3-6 years_ Every 7-10 years_Less often than every 10 years

Rarely or never $\quad$ Rarely or never (because I'm a new employee)

How long have you worked with your present team/crew?

The following items are optional. Please answer as many as you wish.

Current Bid/Assignment (Vehicle/Station Number/Shift or Assignment)

How far do you live from work? Very Far Far _ Neutral

Years of employment with Department ___ Total years of employment

Close - Very close

Rank Age Male/Female Ethnicity

Name 
SHARON ANNE ISRAEL DOLFI

August 17, 1963 Born, New York, New York

1984

Bachelor of Science, Psychology Newcomb College of Tulane University New Orleans, Louisiana

1987

Master of Public Administration Florida International University Miami, Elorida

1987

Graduate Certificate in Public Personnel Management and Labor Relations Florida International University Miami, Florida

Doctor of Philosophy, Psychology (Industrial/Organizational Psychology) Florida International University Miami, Florida

Personnel Administrator, Planner Metro-Dade County (Police and Fire Rescue Departments) Miami, Florida

\section{PRESENTATION}

Dolfi, S. I., \& Fraser, S. L. (1995). Union and organizational commitment and participation among Eastern Airlines employees. Paper presented at the Tenth Annual Conference of the Society for Industrial and organizational Psychology, orlando, FL, May. 